\title{
Effect of Pre-chamber Enrichment on Lean Burn Pre-chamber Spark Ignition Combustion Concept with a Narrow-throat Geometry
}

\author{
Author, co-author (Do NOT enter this information. It will be pulled from participant tab in \\ MyTechZone) \\ Affiliation (Do NOT enter this information. It will be pulled from participant tab in MyTechZone)
}

\begin{abstract}
Pre-chamber spark ignition (PCSI) combustion is an emerging leanburn combustion mode capable of extending the lean operation limit of an engine. The favorable characteristic of short combustion duration at the lean condition of PCSI results in high efficiencies compared to conventional spark ignition combustion. Since the engine operation is typically lean, PCSI can significantly reduce engine-out NOx emissions while maintaining short combustion durations. In this study, experiments were conducted on a heavyduty engine at lean conditions at mid to low load. Two major studies were performed. In the first study, the total fuel energy input to the engine was fixed while the intake pressure was varied, resulting in varying the global excess air ratio. In the second study, the intake pressure was fixed while the amount of fuel was changed to alter the global excess air ratio. At each global excess air ratio, the fuel injection to the pre-chamber was varied parametrically to assess the effect of pre-chamber enrichment on engine operating characteristics. Multi-chamber heat release analysis was performed to present the pre-chamber and main chamber heat release characteristics separately. The discharge coefficient of the prechamber nozzles was determined by the model calibration to match the pre-chamber and main chamber pressure traces in the GT Power software. The analyzed data reveals a two-stage combustion mechanism in the main chamber where the latter stage is thought to be contributing to the bulk ignition of the main chamber charge. The pre-chamber heat release is correlated to the mixture strength of the pre-chamber, which affects the phasing of the pre-chamber combustion and the initial heat release in the main chamber. As the global excess air ratio becomes lean, the combustion efficiency deteriorates with high $\mathrm{HC}$ and $\mathrm{CO}$ emissions, while $\mathrm{NOx}$ emission declines significantly. The resulting heat release data is presented alongside the engine-out specific emissions.
\end{abstract}

\section{Introduction}

With the new emission regulations enforcing greenhouse gas reduction, the demand for higher efficiency engines have been unprecedently high in recent years [1]. By employing more efficient engines in the fleet for various modes of transportation such as lightduty, heavy-duty, and marine applications, the overall carbon emissions could be reduced. In addition, local emissions such as NOx emission are also part of the problem as they affect human health adversely. Hence, modern engine research focuses not only on efficient combustion but also on suppression of criteria pollutants as much as possible. Other than improving engine efficiency, a longterm solution to carbon neutrality requires operating the heat engines

Page 1 of 19 using fuels derived from carbon-neutral sources such as biofuels and green methane.

However, the high-volume production of synthetic fuels and biofuels have yet to be developed to become a primary fuel source for the transportation sector. The study carried out in 2013 by the European Commission's Joint Research Council projected that the availability of current bioethanol and biodiesel is not sufficient to achieve $10 \%$ renewable energy in the transport sector [2]. One interim approach suggested for carbon reduction is to employ fuels with higher hydrogen-to-carbon ratios, which have the inherent benefit of lower carbon dioxide emission for a given mass of fuel. Natural gas, being primarily composed of methane $\left(\mathrm{CH}_{4}\right)$, satisfies such requirements for short-term carbon reduction and has been predicted for a higher utilization rate in the near future [3].

The regulatory pressures imposed on engine manufacturers have shifted the research focus towards lean combustion technologies, which could potentially improve the efficiencies of current engines. The low-temperature combustion (LTC) or lean operation has shown to be very effective in reducing local emission species such as NOx while it could also improve the engine out efficiency. However, the low ignitability of methane, a major component of natural gas, imposed a challenge, especially at lean conditions. Conventional combustion modes, such as spark ignition, may lead to high combustion variability. In recent years, the pre-chamber combustion systems have been increasingly recognized for the reliable ignition of natural gas and the engine efficiency improvements in addition to reduced NOx formations.

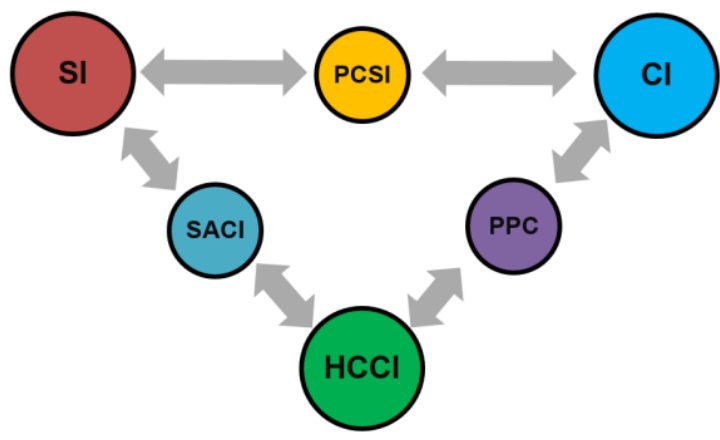

Figure 1 - Current combustion modes

In Figure 1, the current research areas in terms of combustion regimes were illustrated. In between the SI and CI modes, there 
exists a unique combustion technique, typically known as prechamber spark ignition (PCSI) combustion. In PCSI, the combustion process or rather processes are divided into two chambers known as the pre-chamber and the main chamber. The latter refers to a typical combustion chamber found in internal combustion engines.

The pre-chamber is a small chamber, normally ranging less than $10 \%$ of the engine clearance volume and contains several nozzles that connect the pre-chamber to the main chamber. The pre-chamber is equipped with a spark plug that is triggered to start the combustion process. The combustion process initiates with a flame propagation inside the pre-chamber and causes a pressure rise, resulting in a net pressure difference between the pre-chamber and the main chamber. The pressure difference causes mass transfer between the two chambers, which purges the contents of pre-chamber combustion in the form of turbulent jets that burn the lean main chamber charge. The main chamber ignition process is driven by turbulent mixing of the reactive pre-chamber jets and the lean main chamber charge. Hence the PCSI combustion mode can be considered as a hybrid between the SI and the CI combustion modes and could be the bridge in raising the efficiency of SI engines to the levels of CI engines.

There are two main types of PCSI, commonly known as active with additional fuel injection into the pre-chamber and passive without pre-chamber fueling. The former strategy is also referred to as a scavenged pre-chamber as the pre-chamber fuel injection is thought to be scavenging the residual gases out of the pre-chamber. Reliable injection of fuel into the pre-chamber is challenging, especially for liquid fuel. Passive pre-chamber modes cannot extend the lean limit significantly, although it can provide fast combustion at slightly lean conditions with a very low cycle-to-cycle variation while avoiding complexities associated with active pre-chambers.

Historically, pre-chambers were found in production engines in the early 1970 s before the development of high-pressure injection systems and stricter emission standards. Concepts such as Compound Vortex Controlled Combustion (CVCC) by Honda [4], Pre-chamber Injection System (PCI) by Volkswagen [5] and Turbulence Generating Pot Engine by Toyota [6] were able to comply with the Japanese and United States emission standards at that time without a catalytic converter [4]. The mechanical complexities associated with the pre-chamber application, such as auxiliary pre-chamber fueling, added engine manufacturing cost, and maintenance expenses, which led to the pre-chambers being phased out of the market around 1985 [7]. However, due to its capability to burn fuels with low ignitability, pre-chambers were retained in gas-fueled engines and is an industry-standard in the stationary power generation engines.

There has been a significant amount of research undertaken in the PCSI combustion by many different groups [8]. The earliest studies were performed by L. A. Gussak, who fathomed that, depending on the nozzle diameter, the jet issued from the pre-chamber could either be hot burned gases or quenched high-velocity jet containing active radicals [9]. Since then, many studies had been performed on the pre-chamber combustion, which evolved to the concept of the turbulent jet ignition (TJI). This concept has demonstrated improvement in specific fuel consumption while emitting singledigit ppm of NOx [10].

However, there still exists a gap in the understanding of PCSI, especially in the combustion phenomenon inside the pre-chamber and the main chamber. Oppenheim [11] studied the physics of prechamber jets in a constant volume combustion chamber and concluded that the pre-chamber jets initiated multiple ignition sites inside the main chamber, which could ignite a very lean charge. The Page 2 of 19 experiments were similar to that of Yamaguchi [12], who performed a detailed investigation into the effect of pre-chamber nozzle diameter. He reported that, with variation in nozzle diameter, the nature of the pre-chamber jets and subsequent main chamber ignition showed different patterns. Biswas and Qiao [13] further examined the pre-chamber jets using the Schlieren and OH-PLIF imaging in a combustion vessel and identified jet ignition phenomenon for some nozzle combinations, as opposed to flame ignition process.

Gentz et al. [14] also provided some insight into the influence of nozzle orifice diameter through visualization of pre-chamber jets using chemiluminescence imaging of $\mathrm{OH}^{*}$ and $\mathrm{CH}^{*}$ radicals in a rapid compression machine. In 2015, Shah et al. [15] assessed the effect of pre-chamber volume and nozzle diameter in a wide range of engine set-ups, the results of which further confirmed the prechamber volume and nozzle area recommended by Gussak. Bardis et al. [16] developed a 0-D and 1-D model using suitable calibration parameters to represent turbulence intensity inside the pre-chamber and heat transfer loss from the pre-chamber, with varying prechamber geometries. Shapiro et al. [17] demonstrated the effect of pre-chamber height using a 3-D CFD model, which was validated with experimental data. Bolla et al. [10] explained the effect of nozzle orientation using the 3-D CFD model.

Through the literature survey, it can be concluded that the prechamber combustion is sensitive to the internal geometry of the prechamber as well as the nozzle design and orientation. From a practical perspective, the illusion that the pre-chamber internal geometry can be chosen to attain the best dynamic flow characteristics is far from reality. Nowadays, the restriction on carbon emissions adds extra pressure to convert existing heavy-duty or marine diesel engines to natural gas applications. In such a conversion scenario, the pre-chamber assembly must be designed to fit the existing diesel injector pocket in the cylinder head. Otherwise, the engine cylinder head must be modified permanently. Avoiding modification of the cylinder head adds incentive to the industry due to shorter downtime in diesel to gas conversion. Moreover, the endusers can also convert back to base diesel setup if desired. The geometry of the pre-chamber, in such a case, would be dictated by the geometrical constraints of the diesel injector pocket.

In the case of active PCSI, the enrichment of the pre-chamber is found to be important, especially in lean limit extension. Attard et al. [18] determined that the addition of fuel equivalent to $2 \%$ of total fuel energy to the pre-chamber led to higher efficiency, approaching $42 \%$ net indicated efficiency. Shah et al. [19] also conducted experiments with various pre-chamber air-to-fuel ratios and observed that a rich pre-chamber mixture is important in extending the lean limit. Since these experiments were performed in prechamber designs with relatively wide throat diameter, it inspired the authors to investigate the effect of fuel enrichment in a narrow throat pre-chamber. Hence, in this study, the effect of pre-chamber enrichment on the PCSI combustion processes was investigated in a heavy-duty research engine using multiple combinations of global and pre-chamber excess air ratios. Heat release analysis was performed, and the emission data was presented alongside the operating characteristics.

\section{Experimental Engine Setup}

The KAUST single-cylinder research engine was outfitted by MESA engine solutions from the base multi-cylinder diesel engine. In the conversion process, five cylinders of the engine were deactivated by removing the intake and exhaust valves. The engine 
components such as intake and exhaust manifolds were modified to allow for the single-cylinder operation of the engine. The geometrical compression ratio of the engine was reduced to 11.5 by replacing the original piston with a modified one, featuring a modified bowl geometry. For PCSI experiments, port fuel injectors were installed in the modified intake manifold. The central diesel injector was replaced with a pre-chamber assembly, which was designed according to the outside dimensions of the stock diesel injector. The engine specifications can be found in Table 1 .

Table 1 - Experimental engine specifications

\begin{tabular}{|l|l|l|}
\hline Engine Model & \multicolumn{2}{|l|}{ Volvo D13C500 } \\
\hline Control System & \multicolumn{2}{|l|}{ NI LabVIEW } \\
\hline Piston Shape & \multicolumn{2}{|l|}{ Bowl-in-piston } \\
\hline Valve Mechanism & \multicolumn{2}{|l|}{ Single Overhead Cam } \\
\hline Number of Valves & 2-Intake 2-Exhaust \\
\hline Bore & 131 & {$[\mathrm{~mm}]$} \\
\hline Stroke & 158 & {$[\mathrm{~mm}]$} \\
\hline Connecting Rod Length & 255 & {$[\mathrm{~mm}]$} \\
\hline Comp. Ratio & 11.5 & {$[-]$} \\
\hline Displacement & 2.1 & {$[\mathrm{~L}]$} \\
\hline Intake Valve Timing & $\begin{array}{l}\text { Open } \\
\text { Close }\end{array}$ & $\begin{array}{l}-330 \text { CAD aTDC } \\
-130 \text { CAD aTDC }\end{array}$ \\
\hline \multirow{2}{*}{ Exhaust Valve Timing } & $\begin{array}{l}\text { Open } \\
\text { Close }\end{array}$ & $\begin{array}{l}\text { 180 CAD aTDC } \\
\text {-340 CAD aTDC }\end{array}$ \\
\hline
\end{tabular}

The engine speed was kept constant by the ABB motor drive, which also performed as a dynamometer. Exhaust gas emissions were measured by a Horiba MEXA 1700 exhaust gas analyzer. Temperature and pressure sensors were installed to measure the conditions of intake air, exhaust, engine coolant, and lubrication oil. Two piezoelectric pressure sensors were installed in the main chamber and the pre-chamber respectively to measure the evolution of pressure with 0.2 crank angle degree resolution. In addition, two high-resolution piezoresistive pressure sensors were installed in the intake and exhaust to measure the pressure traces with a 0.2 crank angle degree resolution.

The gaseous fuel supply line was prepared for the fuel addition to both the pre-chamber and the main chamber. The gas fuel line from the gas cylinder cabinets was divided into two branches. Each branch enters a damping vessel, the purpose of which was to reduce pressure fluctuations. The outlet from each damping vessel was connected to a mass flow controller, which measured and controlled the volumetric flow rate to the engine. The outlet of each controller supplied the fuel to the respective injectors. The SLA5850 and the SLA5853 model of thermal mass flow controllers from Brooks were used for the pre-chamber and main chamber fuel flow, respectively. Two Bosch NGI-2 injectors were installed in the intake air manifold for the main chamber fuel. A SP-021 injector from the Clean Air Power was used to control the timing of pre-chamber fuel injection.

In the case of the pre-chamber, the injector was opened sufficiently long to allow the regulation of flow rate by the pre-chamber mass flow controller. In other words, the amount of pre-chamber fuel was regulated by the mass flow controller, while the injector operation determined the timing of fuel injection. This method was adopted since the experiments required accurate metering of the pre-chamber fuel flow rate. The main chamber injectors were needed to be open for a significantly longer duration of injection due to the low flow rate of the injectors and the high fuel consumption rate of the engine. Hence, controlling the main chamber fuel flow by the mass flow controller takes significant time to reach the desired setpoint. Instead, the mass of fuel injection was controlled by the injector duration of opening (DOI), and the mass flow controller was used to measure the fuel flow rate to the intake. The schematic diagram of the test-cell is shown in Figure 2.

A NI-based real-time embedded control system was used to control engine operating parameters and to acquire data from the test-cell. The engine control and data acquisition (DAQ) system was based on LabVIEW programming utilizing the NI-CompactRIO, into which several NI C-series modules with dedicated functions were installed. A crank encoder with a 0.2 crank angle degree resolution was fitted onto the crankshaft to synchronize the engine control signals. The CompactRIO communicated with the host PC, where the user manipulated the engine control parameters. The system also collected real-time data during the experiments and sent data queues to the host computer.

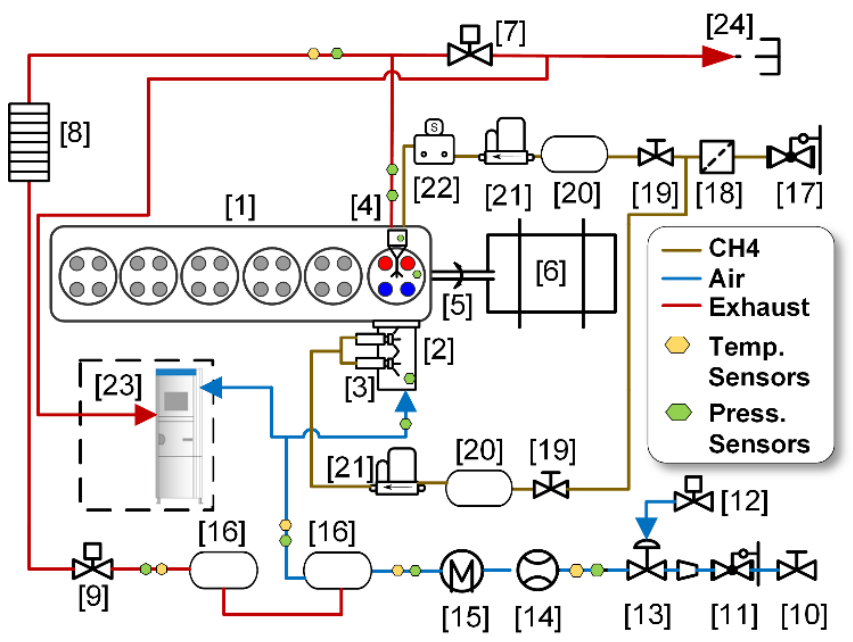

Figure 2 - Schematic diagram of the experimental setup: 1. Engine, 2. Intake manifold, 3. Port fuel injectors, 4. Pre-chamber, 5. Cardan shaft, 6. Dynamometer, 7. Back pressure valve, 8. EGR Cooler, 9. EGR valve, 10. Main air valve, 11. Pressure regulator, 12. Control air valve, 13. Intake throttle valve, 14. Air flowmeter, 15. Air heater, 16. Mixing Tank, 17. Main gas fuel valve, 18. Gas fuel filter, 19. Valve, 20. Pressure damping vessel, 21. Mass flow controllers, 22. Pre-chamber injector, 23. Horiba exhaust analyzer, 24. Vent to the atmosphere

\section{Pre-chamber Design}

The pre-chamber volume and nozzle area-to-pre-chamber volume ratio recommended by Gussak [9] was adopted for the pre-chamber design. As indicated in the introduction section, the pre-chamber was designed with the intention to fit the whole assembly inside the unmodified diesel injector pocket. Hence, the outside dimensions of the pre-chamber were confined by the dimensional constraints of the internal dimensions of the injector pocket. The design constraints dictated the shape of the pre-chamber, which resulted in a narrowthroat pre-chamber design. Since the tip of the pre-chamber was very small, it was not possible to distribute the desired nozzle area along the periphery of the pre-chamber tip in a single row in any combination of the number of nozzles and nozzle diameters.

Hence, the total number of nozzles was selected to be 12 , and it was decided to distribute the nozzles in two different layers, each containing six nozzles. The two layers were offset by 15 degrees to cover the whole combustion chamber axisymmetrically with the 12 nozzles. After the machining process, some inaccuracies in the dimensions were detected. The actual nozzle diameter of the fabricated pre-chamber differed from the design target, which

Page 3 of 19 
displaced the pre-chamber nozzle area to volume ratio from the recommended parameters by Gussak. The design dimensions of the pre-chamber against the actual dimensions were shown below in Table 2, and the internal geometry of the pre-chamber was illustrated in Figure 3.

The pre-chamber assembly consists of three main parts, the prechamber body, the pre-chamber adaptor, and the enclosure. The body was made of Inconel 625 for high-temperature resistance relevant to in-cylinder combustion temperatures. The pre-chamber body is screwed onto the pre-chamber adaptor, which houses the auxiliary components essential for PCSI combustion. This part was manufactured in aluminum bronze alloy for improved heat dissipation rates from the pre-chamber to the engine cylinder head. The adaptor accommodates a NGK-ER9EH spark plug and an AVLGH15DK piezoelectric pressure sensor.

Table 2 - Pre-chamber geometrical parameters

\begin{tabular}{|l|l|l|l|}
\hline Parameter & Design & Actual & Unit \\
\hline Pre-chamber Volume & 5.07 & 5.07 & {$[\mathrm{cc}]$} \\
\hline Pre-chamber Vol./Clearance Vol. & 2.5 & 2.5 & {$[\%]$} \\
\hline Number of Nozzles & 12 & 12 & {$[-]$} \\
\hline Nozzle Diameter & 1.37 & 1.50 & {$[\mathrm{~mm}]$} \\
\hline Nozzle Area: Pre-chamber Volume & 0.035 & 0.042 & {$\left[\mathrm{~cm}^{-1}\right]$} \\
\hline Nozzle Included Angle (Upper and Lower Ring) & 134 & 134 & {$[\mathrm{deg}]$} \\
\hline Throat Diameter & 3.25 & 3.30 & {$[\mathrm{~mm}]$} \\
\hline Throat Length & 25 & 25 & {$[\mathrm{~mm}]$} \\
\hline
\end{tabular}

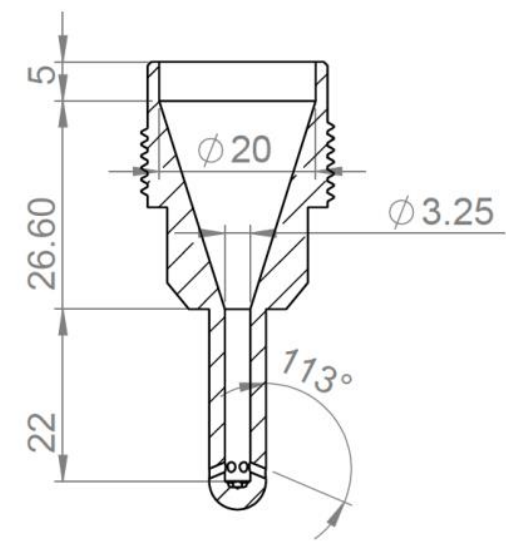

Figure 3 - Cross-section view of the pre-chamber

A channel was drilled into the pre-chamber body for the installation of a 558 series miniature check valve from the Lee company. The check valve is deformed-fitted into the channel and allows fuel injection into the pre-chamber during the gas exchange period. The gas supply pipe is secured at the entrance of the channel on the top surface of the pre-chamber adaptor. The pre-chamber enclosure acts as a spacer, which enables clamping down the whole pre-chamber assembly by the modified clamp, similar to a diesel injector clamp. The enclosure also seals the pre-chamber assembly from the diesel fuel channel, reminiscence of the base diesel engine. The exploded view of the pre-chamber assembly is shown in Figure 4. The installation of the pre-chamber assembly inside the injector pocket is illustrated in Figure 5.

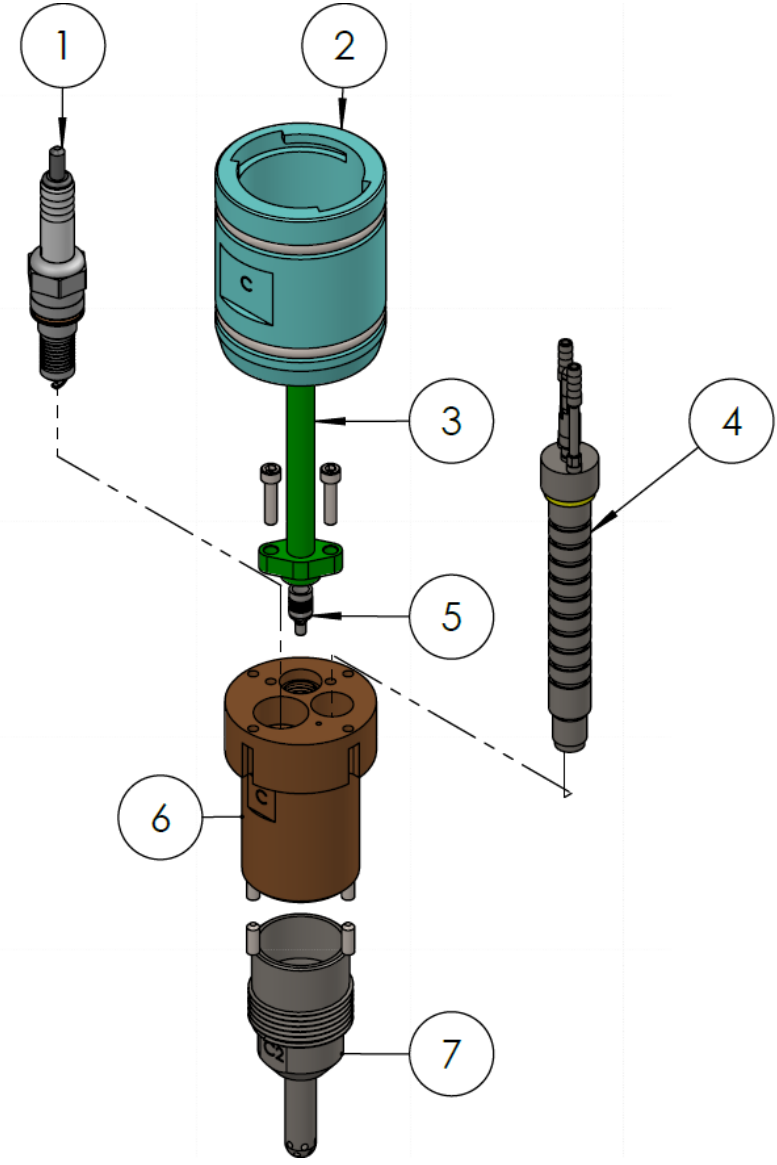

Figure 4 - Exploded view of the pre-chamber assembly: 1 . Spark plug, 2 Enclosure, 3. Gas supply pipe, 4. Piezoelectric pressure sensor, 5. Miniature check valve, 6. Pre-chamber adaptor, 7. Pre-chamber body

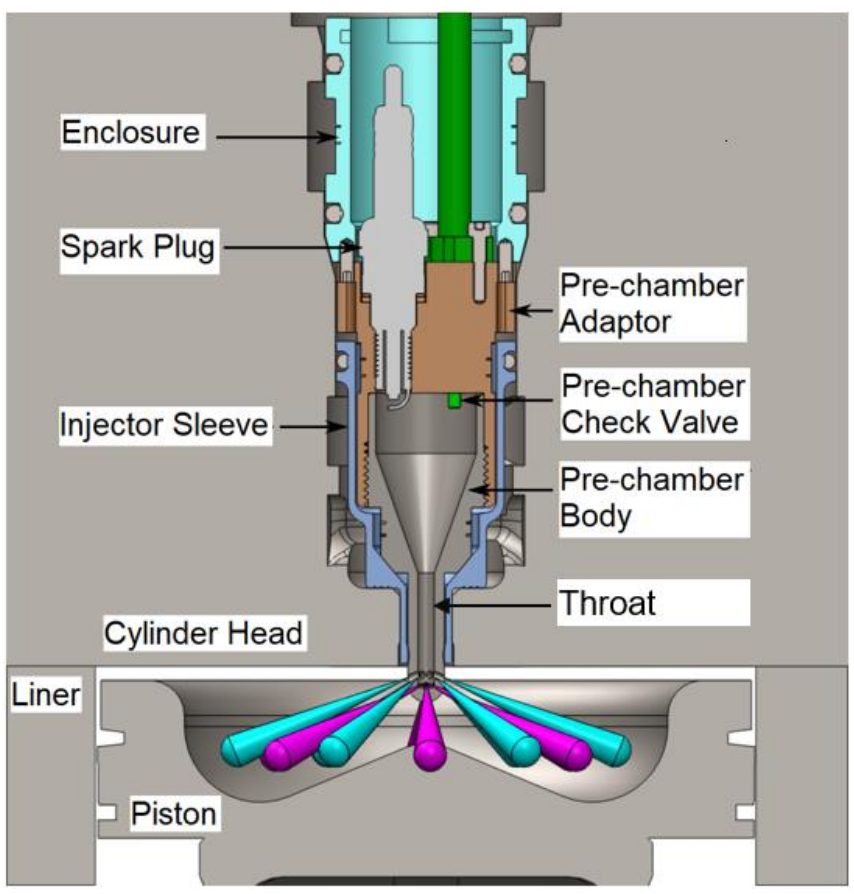

Figure 5 - Cross-section view of the pre-chamber installation 


\section{Operating Conditions and Methodology}

The experiments were conducted using two different methodologies. In the first methodology, the fuel energy input to the engine or the fuel mean effective pressure (FuelMEP) was kept constant at $26.4 \pm$ 1.2 bar throughout the experiments. The equation for FuelMEP is mentioned in equation (5) in the following sections. This dataset will be referred to as the global excess air ratio (global $\lambda$ ) sweep with constant fuel flow in the following sections. The standard deviation in FuelMEP is due to deviations in the fuel flow rate to the engine. The intake pressure was varied from 1.3 bar to 2.0 bar, which resulted in increased global $\lambda$ conditions. For each global $\lambda$, the prechamber enrichment, represented by the pre-chamber excess air ratio (pre-chamber $\lambda$ ), was varied to examine the effect of pre-chamber enrichment.

In the second methodology, which will be referred to as the global $\lambda$ sweep with the constant airflow, the intake pressure was kept constant at 1.5 bar while the fuel input was progressively reduced to result in lean operating conditions. Hence, the load was varied from 11 bar to 6.5 bar IMEP. Similar to the first methodology, the prechamber $\lambda$ was varied at each load to determine the effect of prechamber enrichment. In both methodologies, the pressure difference between the exhaust and the intake was kept constant at $0.2 \pm 0.05$ bar to mimic the real engine operation with a turbocharger.

The main reason for performing global $\lambda$ sweep with both constant fuel flow and constant airflow was to examine the performance and emission characteristics of PCSI at two different lean scenarios, which were the variation of intake pressure while maintaining a constant fuel input, and the variation of fuel input while maintaining a constant intake pressure. The second methodology was representative of load variation in a normal drive cycle covering medium to low load while the first was to identify the optimal operating point for a particular load condition. In both methodologies, at each global $\lambda$, the ratio of fuel energy injected through the pre-chamber over the total fuel energy input to the engine was varied, resulting in different pre-chamber $\lambda$.

For both the pre-chamber and main chamber, methane with $99.5 \%$ purity was chosen as the sole fuel for the experiments. The fuel injection timing of both the pre-chamber and main chamber injectors was set at -360 CAD aTDC. The cam timing of the engine was such that the intake and exhaust valve overlap was negligible, and the initial test runs confirmed that there was no fuel loss to exhaust during the injection events. The fuel supply pressure was fixed at 7 bar for both the pre-chamber and the main chamber injectors. The pre-chamber fuel injection was determined by the backpressure acting on the miniature check valve residing inside the adaptor.

The combustion stability limit of the engine was set at $5 \%$ of the coefficient of variation of gross IMEP, although some data points exceeding the limit are presented in the paper. The knock limit was defined at the knock intensity of 0.5 bar, where the parameter was acquired from the maximum amplitude of the bandpass-filtered main chamber pressure signal. The frequency band for knock intensity calculation is between $4 \mathrm{kHz}$ and $18 \mathrm{kHz}$. At all data points, the spark timing was fixed at $-15 \mathrm{CAD}$ aTDC to conserve the flow field inside the pre-chamber for each intake pressure condition. The operating conditions in the two methodologies were tabulated in Table 3.
Table 3 - Operating conditions: Methodology 1 and Methodology 2

\begin{tabular}{|c|c|c|c|}
\hline & Methodology 1 & Methodology 2 & Units \\
\hline Engine Speed & 1200 & 1200 & RPM \\
\hline Coolant Temp. & $78 \pm 2$ & $78 \pm 2$ & ${ }^{\circ} \mathrm{C}$ \\
\hline Lub. Oil Temp. & $80 \pm 2$ & $80 \pm 2$ & ${ }^{\circ} \mathrm{C}$ \\
\hline Intake Temp. & $30 \pm 1$ & $30 \pm 1$ & ${ }^{\circ} \mathrm{C}$ \\
\hline Intake Press. & $1.3,1.5,1.7,1.9,2.0$ & 1.5 & bar \\
\hline Exhaust $\Delta \mathrm{P}$ & $0.2 \pm 0.05$ & $0.2 \pm 0.05$ & bar \\
\hline MC Fuel & \multicolumn{3}{|c|}{$\mathrm{CH}_{4}$ Gas $(99.5 \%$ purity) } \\
\hline MC Fuel SOI & -360 & -360 & CAD aTDC \\
\hline MC Fuel Press. & 7 & 7 & CAD aTDC \\
\hline PC Fuel & \multicolumn{3}{|c|}{$\mathrm{CH}_{4}$ Gas $(99.5 \%$ purity) } \\
\hline PC Fuel SOI & -360 & -360 & bar \\
\hline PC Fuel Press. & 7 & 7 & bar \\
\hline
\end{tabular}

\section{Heat Release Analysis}

The multi-chamber heat release analysis method introduced by Duong et al. [20] is followed to predict the rate of heat release from the pre-chamber and main chamber separately. Based on the first law of thermodynamics, the heat release from the pre-chamber and main chamber can be derived. The heat release rate in the main chamber, derived from the main chamber pressure trace, is shown in equation (1)

$$
\frac{d Q_{M C}}{d \theta}=\frac{\gamma}{\gamma-1} P_{M C} \frac{d V_{M C}}{d \theta}+\frac{1}{\gamma-1} V_{M C} \frac{d P_{M C}}{d \theta}-C_{P} T_{P C, M C} \frac{d m}{d \theta}
$$

The pre-chamber heat release rate can be expressed, as shown in equation (2). The terms in equation (1) and equation (2) are mentioned in the abbreviations section. Since the pre-chamber volume is fixed, the first term of the heat release equation representing the effect of volume change disappears as shown below.

$$
\frac{d Q_{P C}}{d \theta}=\frac{1}{\gamma-1} V_{P C} \frac{d P_{P C}}{d \theta}+C_{P} T_{P C, M C} \frac{d m}{d \theta}
$$

The specific heat capacity $\left(\mathrm{C}_{\mathrm{P}}\right)$ is calculated based on the mixtureaveraged specific heat values of trapped in-cylinder species. A simplifying assumption is adopted here, assuming that the intermediate species are short-lived, and only stable molecules are considered. The burned mass fraction is estimated based on the pressure rise rates, which is used to determine the portions of reactants and products inside the cylinder at each crank angle position. These mass fraction of reactants over the products is used to calculate the mixture-averaged specific heat capacity at constant pressure. The mass transfer between the pre-chamber and the main chamber is modeled by using a flow equation through a nozzle, as shown in equation (3) [22].

$$
d m=\frac{C_{d} A_{T} P_{P C}}{\sqrt{R T_{P C}}}\left(\frac{P_{M C}}{P_{P C}}\right)^{\frac{1}{\gamma}}\left[\frac{2 \gamma}{\gamma-1}\left(1-\left(\frac{P_{M C}}{P_{P C}}\right)^{\frac{\gamma-1}{\gamma}}\right)\right]^{\frac{1}{\gamma}}
$$


The discharge coefficient of the pre-chamber nozzles is determined from GT Power simulations, by matching the pre-chamber and main chamber pressure traces. The methodology was introduced in the previous work of the authors [21]. For the sake of brevity, a detailed explanation for determining the pre-chamber nozzle discharge coefficient is omitted. Depending on the flow direction, either the main chamber temperature or the pre-chamber temperature is used in the mass transfer part of the heat release equation of the two chambers. In the study, the positive flow direction is taken as when the mass or energy transfer is from the pre-chamber to the main chamber. An opposite convention would only swap the positive to negative values, and the overall magnitude of heat release would not change, and hence, the convention is arbitrary.

\section{Pre-chamber Excess Air Ratio ( $\lambda$ ) Estimation}

For passive or unfueled pre-chamber, it is assumed that the main chamber charge is fully premixed, and hence the pre-chamber and main chamber have the same excess air ratio. For the active or fueled-pre-chamber, determining or estimating the excess air ratio inside the pre-chamber at the time of spark is complex and requires two estimations: (a) the amount of fuel trapped inside the prechamber after the injection event and (b) the amount of lean main chamber air-fuel mixture pushed into the pre-chamber during the compression stroke up to the spark timing. Estimating these two parameters is complex and requires assumptions to simplify the calculation.

At high pre-chamber fuel injection rates, the total volume of the injected fuel would exceed the pre-chamber geometrical volume, and the fuel would spill out of the pre-chamber. An assumption here is made that the pre-chamber can only trap the volume of fuel injected less than or equivalent to its geometrical volume. The surplus fuel is thought to be spilled to the main chamber via the prechamber nozzles. For high pre-chamber fuel injection rates, the determination of the trapped fuel mass is dependent on the assumption of spilled fuel. Here, the terminology from the twostroke engine gas exchange process is borrowed to present the two possibilities which can happen to the spilled fuel.

1. Perfect displacement scenario: The spilled fuel is pushed back into the pre-chamber during the compression stroke. The pre-chamber regains the spilled fuel and retains all the fuel injected into the pre-chamber.

2. Perfect mixing scenario: The spilled fuel instantaneously mixes with the main chamber air-fuel mixture. The latter is, thus, further enriched. The pre-chamber can only trap the amount of fuel equivalent to its geometrical volume, and the rest is lost to the main chamber.

Logically, the realistic scenario should be in between these two assumptions. Due to the nature of the engine experiments, the proportions of fuel retained and loss cannot be measured. Here, for the sake of simplicity, it is assumed that the residuals in the prechamber are flushed with injected fuel, and the full extent of the prechamber can be filled up with fuel. The amount of main chamber mixture pushed into the pre-chamber during the compression stroke further dilutes the pre-chamber and must be considered in estimating the equivalence ratio in the pre-chamber. Gussak [23] employed a simple model, relying on the instantaneous compression ratio to estimate the influx of main chamber air-fuel mixture into the prechamber during the compression stroke. In his studies, air-fuel mixtures were injected into the pre-chamber in contrast to modern active pre-chamber modes where only fuel is injected.
Shah et al. [19] modified Gussak's model to apply to only fuel addition into the pre-chamber, and this methodology is adopted in this study. The details equations used by Shah would not be repeated here. The pre-chamber $\lambda$ for all the data-points are plotted in Figure 6 for the global $\lambda$ sweep with constant fuel flow, and Figure 7 for the global $\lambda$ sweep with constant airflow. For the perfect mixing scenario, the pre-chamber $\lambda$ cannot be enriched below a certain limit for a given global $\lambda$, represented by the dashed line, as shown in Figure 6 and Figure 7.

The purpose of presenting these variations in the estimation of the pre-chamber $\lambda$ is to make the impression that determining the enrichment level of the pre-chamber would vary depending on the simplifications and assumptions. However, the pre-chamber $\lambda$ is an important parameter that could tie fundamental studies with engine experiments. Hence, the outcomes of the experiments are communicated based on simplified pre-chamber $\lambda$ calculations.

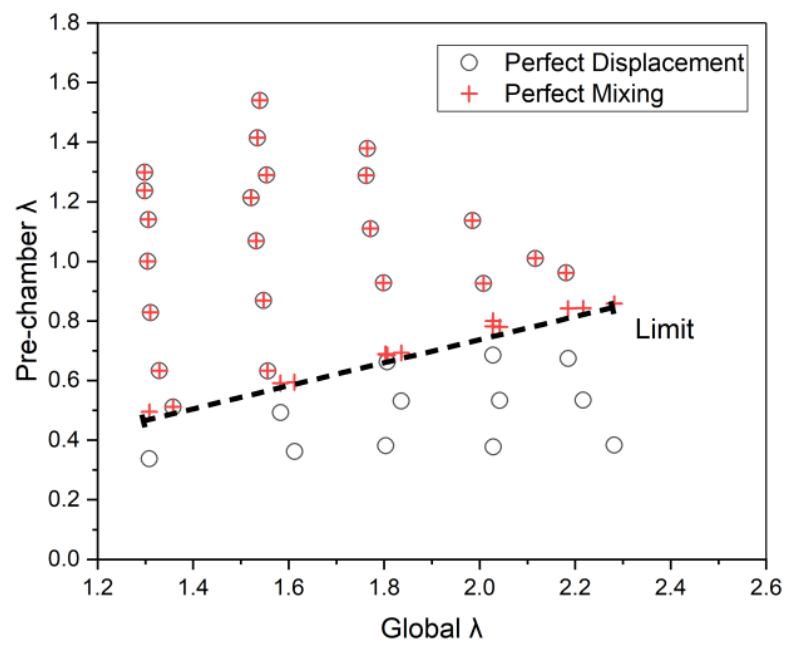

Figure 6 - Global $\lambda$ sweep with constant fuel flow: Pre-chamber $\lambda$ estimation using perfect displacement and perfect mixing assumptions (dashed line represents the rich limit for pre-chamber with perfect mixing assumption.)

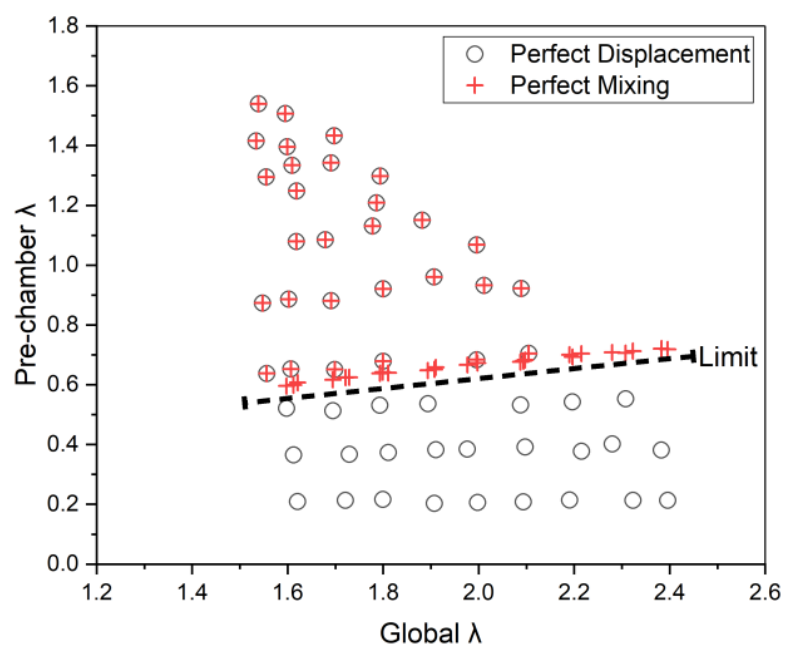

Figure 7 - Global $\lambda$ sweep with constant airflow: Pre-chamber $\lambda$ estimation using perfect displacement and perfect mixing assumptions (dashed line represents the rich limit for pre-chamber with perfect mixing assumption.) 


\section{Results and Discussion}

The results and discussion section is divided into two, first for explaining the general behavior and then the detailed heat release analysis. The general trends in emission and performance of lean PCSI are presented using 2-D contour maps for the global $\lambda$ sweeps with constant fuel flow and constant airflow. Experiments were performed for 200 cycles and averaged values are reported. For the sake of clarity, only the pre-chamber $\lambda$ calculated using the perfect displacement assumption is used throughout the result and discussion section.

In the second section, a more detailed heat release analysis is presented for stable operating points depicting the effect of prechamber enrichment. Three global excess air ratios have been selected from each global $\lambda$ sweep, and the heat release traces are presented for the stable operating points, explaining the change in combustion phasing with variation in the pre-chamber equivalence ratio. The contours of flame development angle, the combustion phasing (CA50) and the combustion duration (CA10-90) are presented in the appendix for all the operating points for the two global $\lambda$ sweep with constant fuel flow and constant airflow, as shown in the Figure B.1 and Figure B.2 of the appendix.

\section{General Trends}

\section{Operating Characteristics}

In the global $\lambda$ sweep with constant fuel flow, although the fuel energy was kept constant, the gross indicated mean effective pressure is different for different operating conditions due to the changes in combustion phasing and combustion efficiency. The resulting gross IMEP from the two data-sets are presented in Figure 8 (a) and Figure 9 (a). In the global $\lambda$ sweep with constant airflow, only the active pre-chamber operation is considered. Since the fuel energy is not conserved in this case, the gross indicated mean effective pressure displays a direct correlation with the global $\lambda$.

At the intake pressure of 1.3 bar, the engine could be operated with stable combustion even without fuel addition to the pre-chamber. As the global $\lambda$ became lean, pre-chamber fuel injection was necessary to maintain combustion stability. The combustion stability measures are presented in Figure 8 (b) and Figure 9 (b).

In Figure 8 (c) and Figure 9 (c), the ratio of fuel mass injected through the pre-chamber to that of the main chamber is presented. In the global $\lambda$ sweep with constant fuel flow, up to $10 \%$ of the main chamber fuel was added through the pre-chamber, whereas in the global $\lambda$ sweep with constant airflow, up to $24 \%$ of the main chamber fuel injection was fed to the pre-chamber. The intention, here, was to investigate a richer pre-chamber $\lambda$ than that of the first global $\lambda$ sweep.

\section{Indicated Specific Emissions}

As shown in Figure 10 and Figure 11, the indicated specific emissions results are found to be a strong function of the overall excess air ratio (global $\lambda$ ). The NOx emissions are excessive in the relatively rich conditions but decline exponentially as the global $\lambda$ increases. Beyond the global $\lambda$ of 1.8 , the specific NOx emission decreases below $1 \mathrm{~g} / \mathrm{kWh}$, as indicated in Figure 10 (a) and Figure 11 (a). The NOx emissions are minimum at the ultra-lean conditions $(\lambda>2.2)$. At these conditions, the combustion stability, which is quantified by the coefficient of variation of gross IMEP is

Page 7 of 19 significantly poor, and caution must be taken in interpreting the results. Since the specific NOx emissions increase exponentially with temperature, the contours in Figure 10 (a) and Figure 11 (a) are presented in exponential scales in contrast to other contours.

Conversely, the specific emissions values for unburned hydrocarbons reduce with the decreasing global $\lambda$, as observed in Figure 10 (b) and Figure 11 (b). As the global $\lambda$ becomes lean, the hydrocarbon emissions increase. The indicated specific carbon monoxide emissions follow the same trend, the value being significant at ultra-lean conditions but insignificant at relatively rich conditions, as shown in Figure 10 (c) and Figure 11 (c). The excessive unburned hydrocarbon emissions and high specific carbon monoxide values can also be attributed to the poor combustion stability at the lean conditions. It is noted here that the specific emission trends are not affected by the variation in the pre-chamber $\lambda$ significantly.

\section{Efficiency}

The combustion efficiency is determined from the emission analysis by equation (4) where $m_{i}$ is the mass of the $\mathrm{i}^{\text {th }}$ emission species, $Q_{L H V, i}$ is the lower heating value of the emission species, $m_{f}$ is the total amount of fuel supplied to the engine, and $Q_{L H V, f}$ is the lower heating value of injected fuel. The mass of emission species, which are unburned hydrocarbons, carbon monoxide, and hydrogen, is calculated from the emission analysis. The fuel means effective pressure (FuelMEP) refers to the total fuel energy supplied to the engine normalized by the engine displacement volume. The combustion losses, thus calculated from the combustion efficiency, subtracted from the fuel mean effective pressure (FuelMEP), results in heat mean effective pressure (QMEP), which refers to the total heat supplied from the combustion process. The gross indicated mean effective pressure (IMEPg) was calculated from the main chamber pressure trace. The thermodynamic efficiency is the ratio of gross IMEP to QMEP which represents the portion of heat energy converted to useful work [22].

$$
\begin{gathered}
\eta_{\text {comb }}=1-\frac{\sum m_{i} Q_{L H V, i}}{m_{f} Q_{L H V, f}} \\
\text { FuelMEP }=\frac{m_{f} Q_{L H V, f}}{V_{\text {Displacement }}}
\end{gathered}
$$

$$
Q M E P=\text { FuelMEP }- \text { Combustion Losses }
$$

$$
\eta_{\text {therm }}=\frac{I M E P g}{Q M E P}
$$

The increases in combustion losses such as carbon monoxide and unburned hydrocarbons led to the reduction of combustion efficiency as the global $\lambda$ becomes lean, as shown in Figure 12 (a) and Figure 13 (a). The thermodynamic efficiency exhibits a monotonic behavior with the global $\lambda$, peaking at the lean limit, representing lower heat transfer losses, as observed in Figure 12 (b) and Figure 13 (b). The gross indicated efficiency, a combined manifestation of the combustion and thermodynamic efficiency, displays a relatively wide plateau of highest-attained efficiency between the global $\lambda$ of 1.6 and 2.0, as indicated in Figure 12 (c) and Figure 13 (c). 


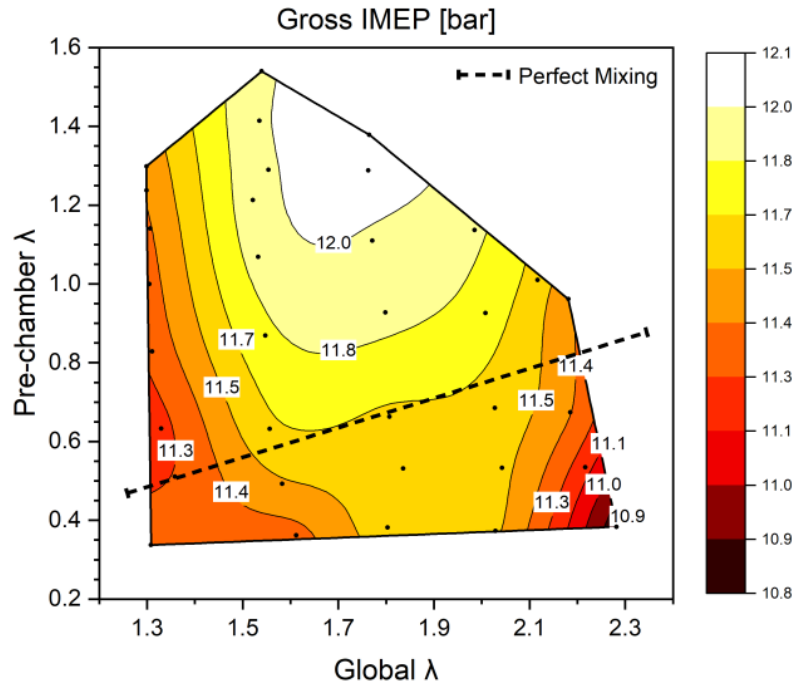

(a)

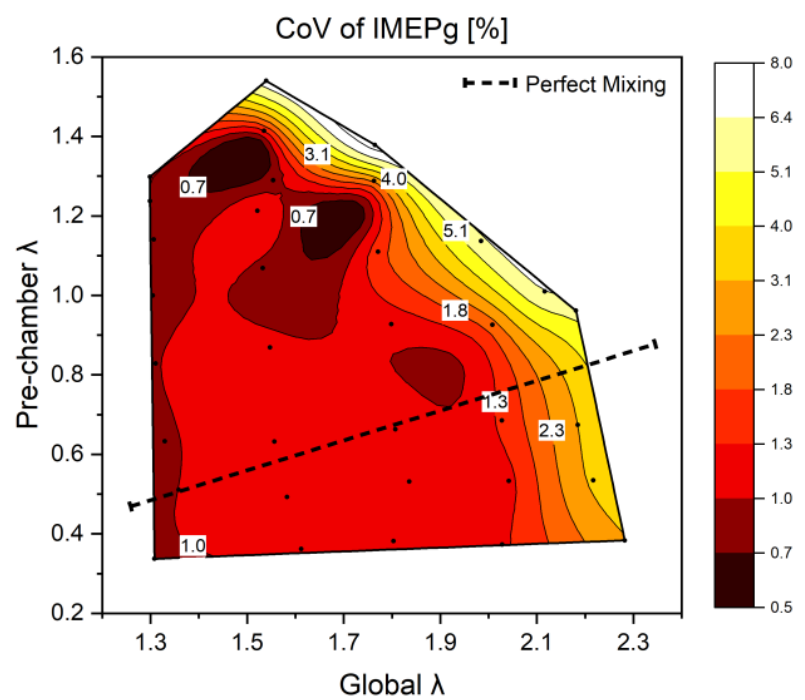

(b)

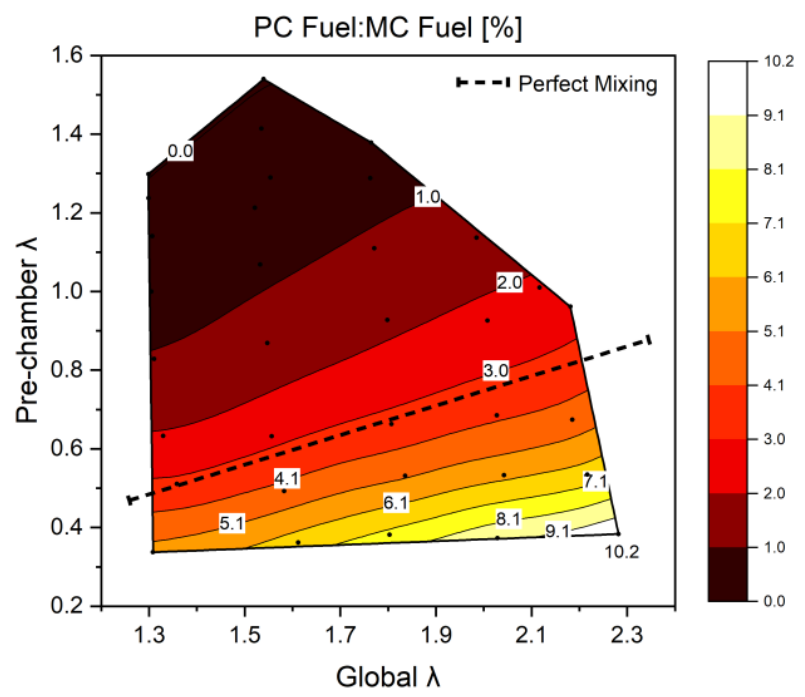

(c)

Figure 8 - Global $\lambda$ sweep with constant fuel flow - General operating characteristics: (a) Gross indicated mean effective pressure, (b) Covariance of gross IMEP and (c) PC fuel/MC fuel ratio

Page 8 of 19

$01 / 28 / 2020$

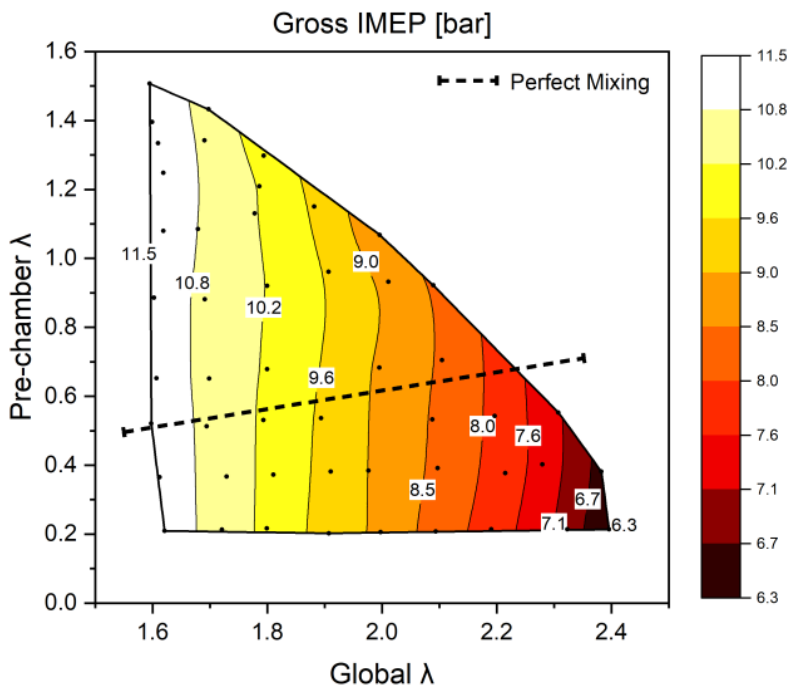

(a)

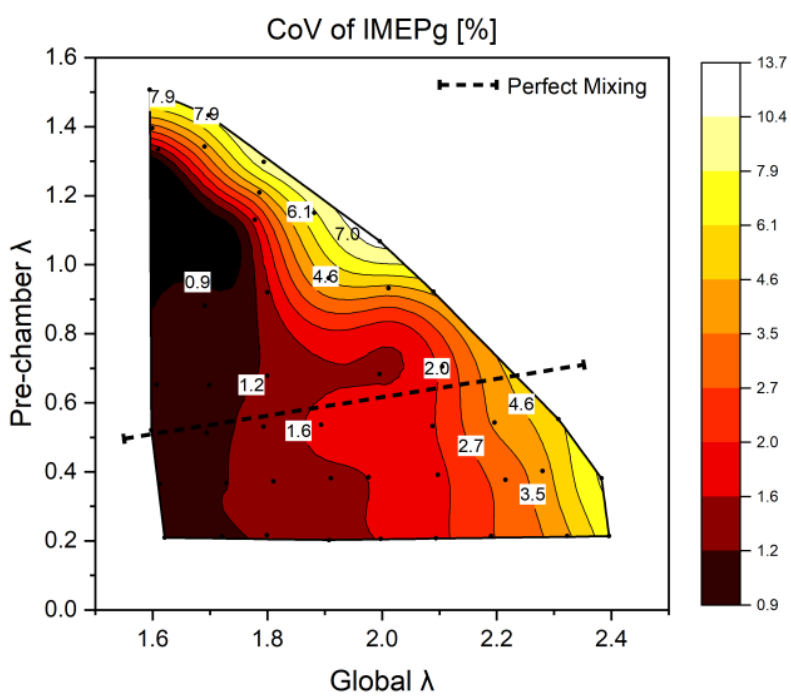

(b)

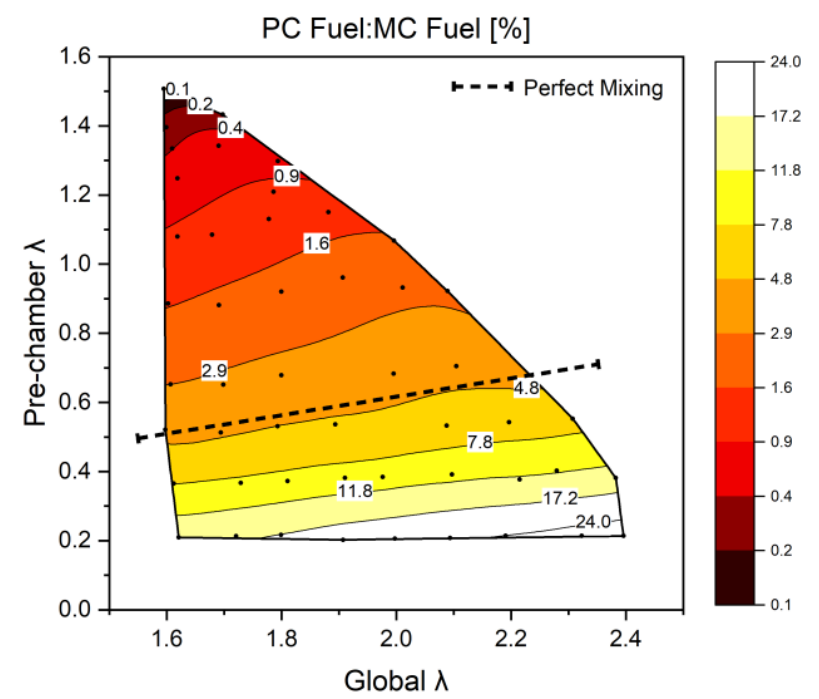

(c)

Figure 9 - Global $\lambda$ sweep with constant airflow - General operating characteristics: (a) Gross indicated mean effective pressure, (b) Covariance of gross IMEP and (c) PC fuel/MC fuel ratio 


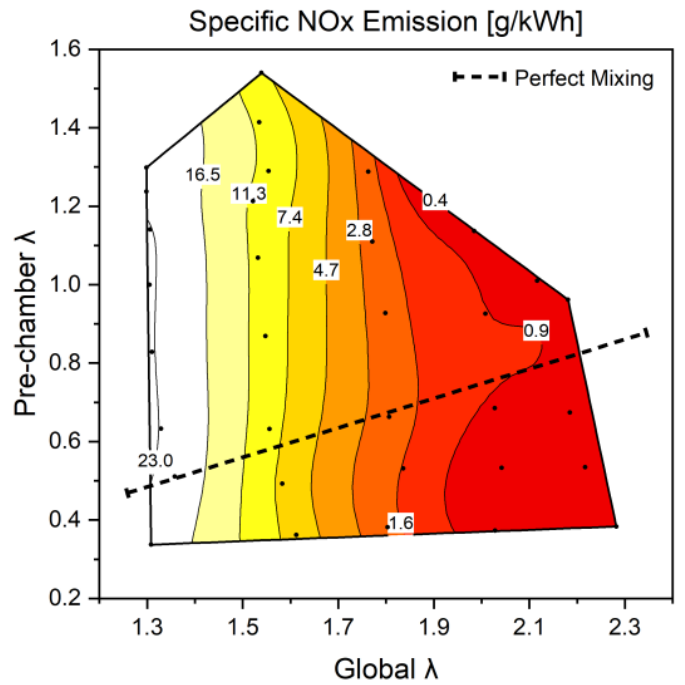

(a)

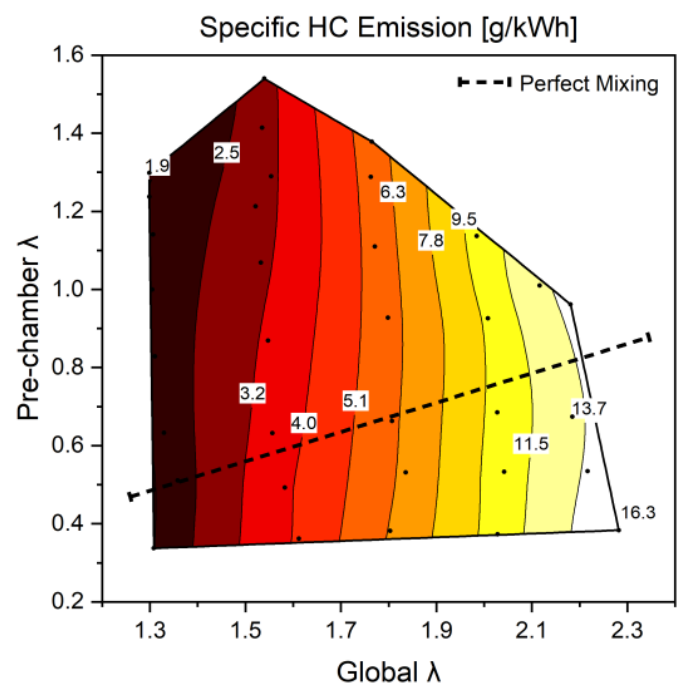

(b)

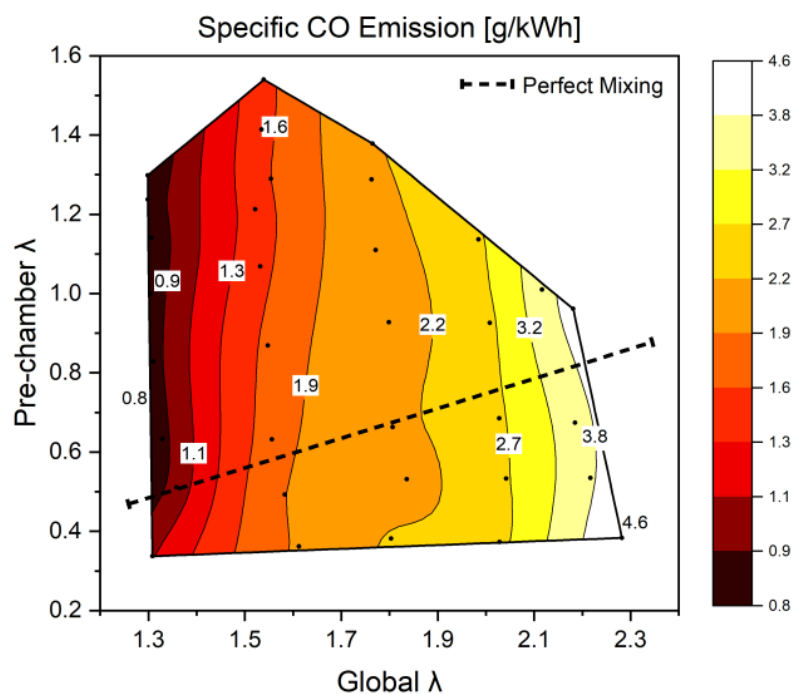

(c)

Figure 10 - Global $\lambda$ sweep with constant fuel flow - Indicated specific emissions: (a) NOx (b) Unburned hydrocarbons and (c) Carbon monoxide

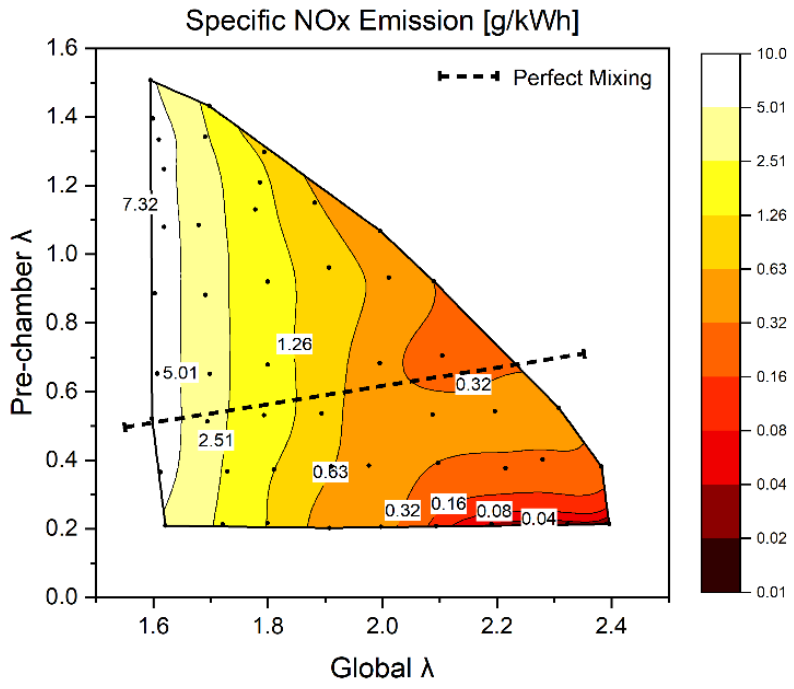

(a)

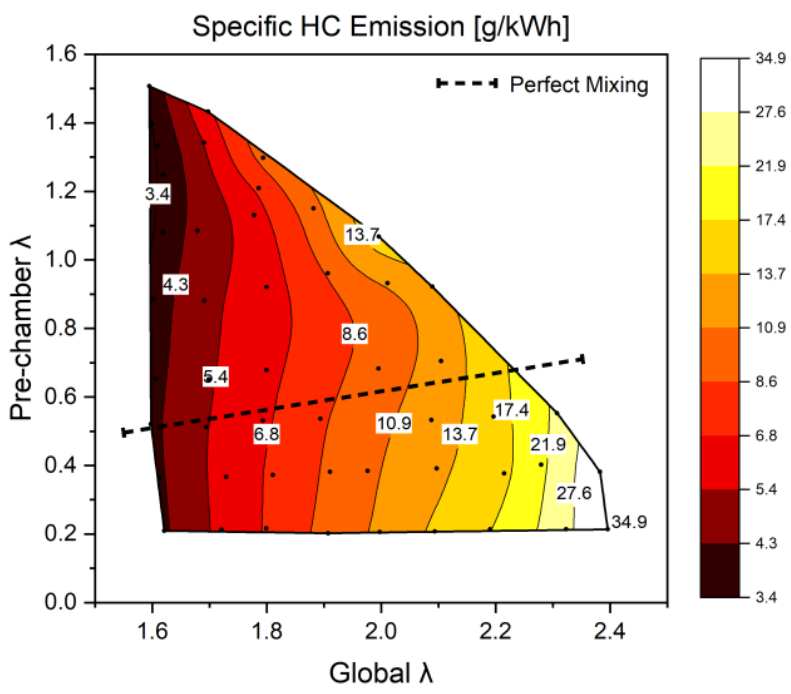

(b)

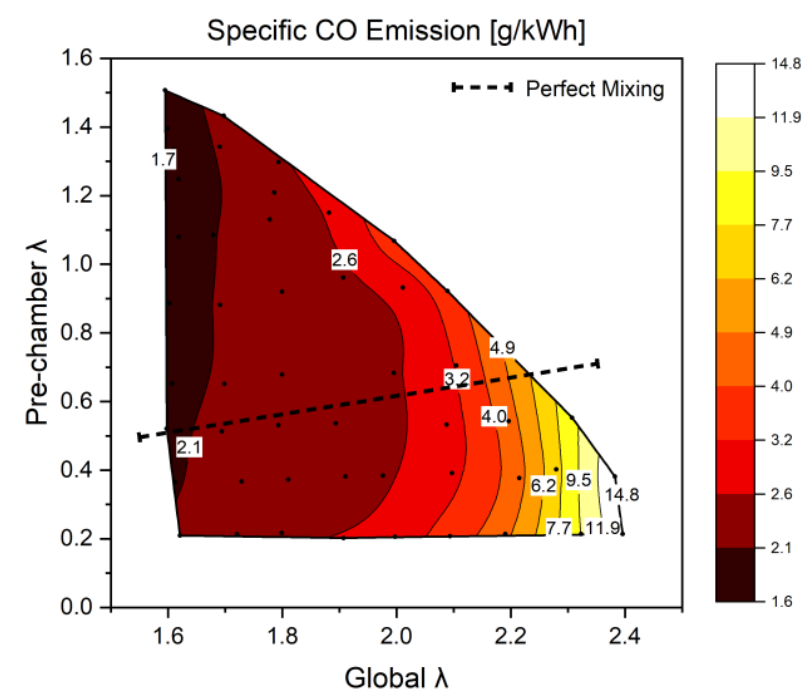

(c)

Figure 11 - Global $\lambda$ sweep with constant airflow - Indicated specific emissions: (a) NOx (b) Unburned hydrocarbons and (c) Carbon monoxide 


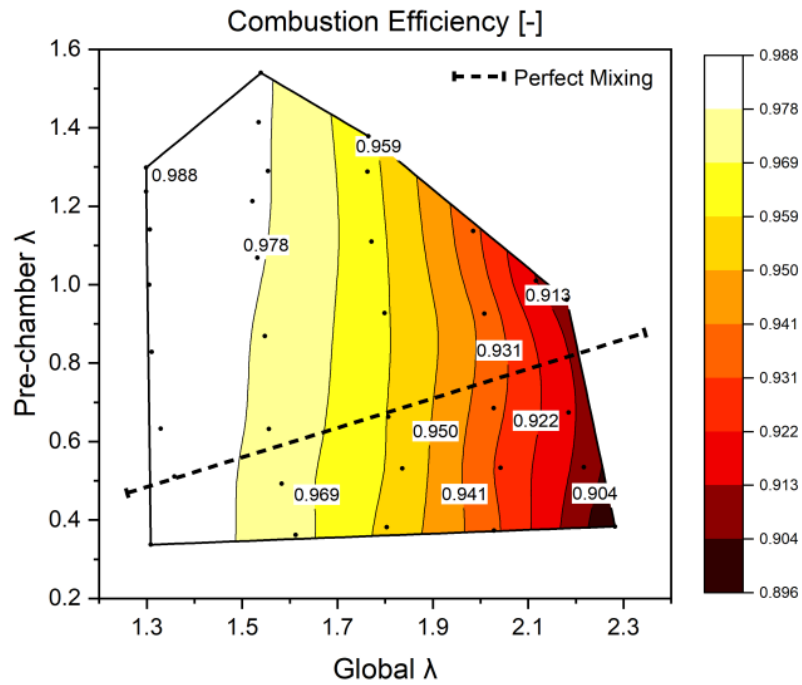

(a)

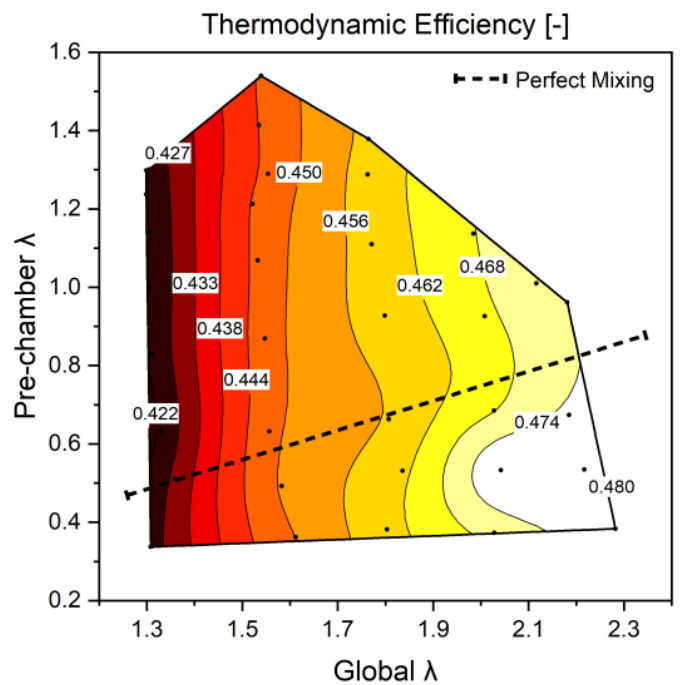

(b)

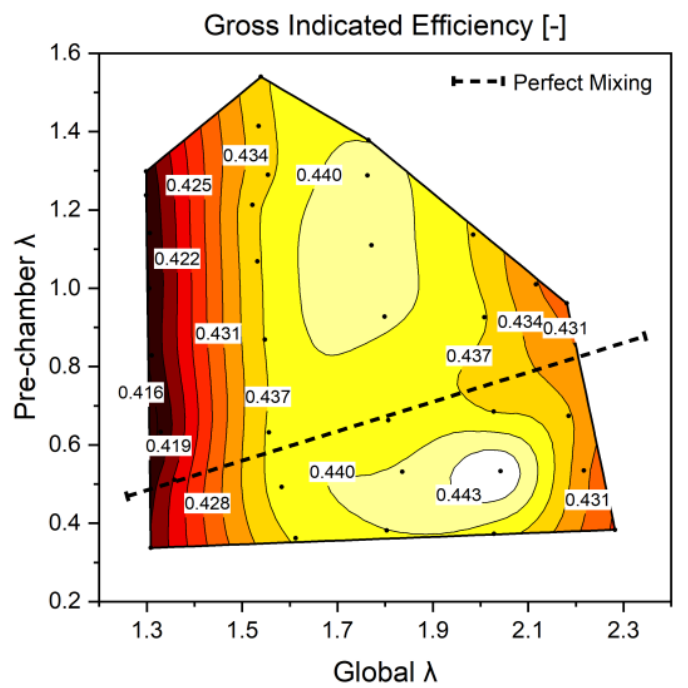

(c)

Figure 12 - Global $\lambda$ sweep with constant fuel flow - Efficiencies: (a) Combustion efficiency, (b) Thermodynamic efficiency and (c) Gross indicated efficiency
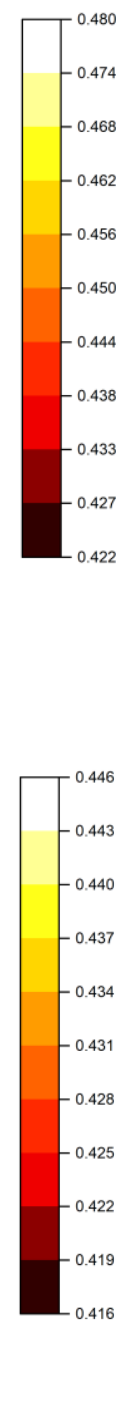

Page 10 of 19

$01 / 28 / 2020$

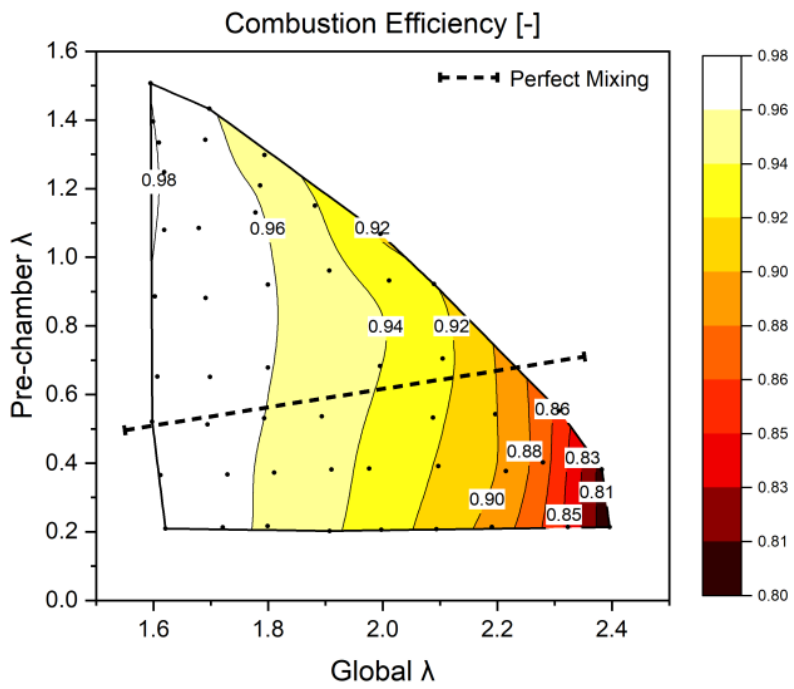

(a)

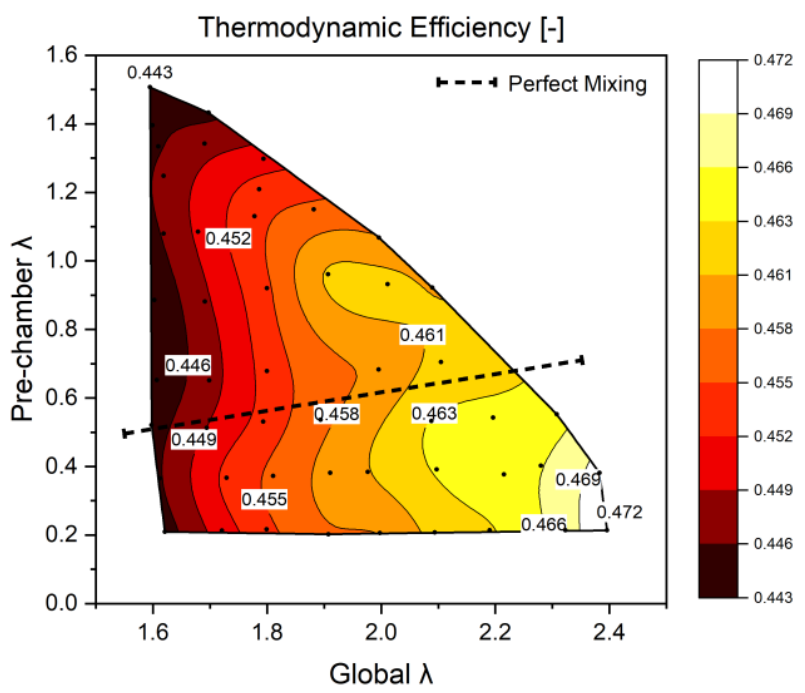

(b)

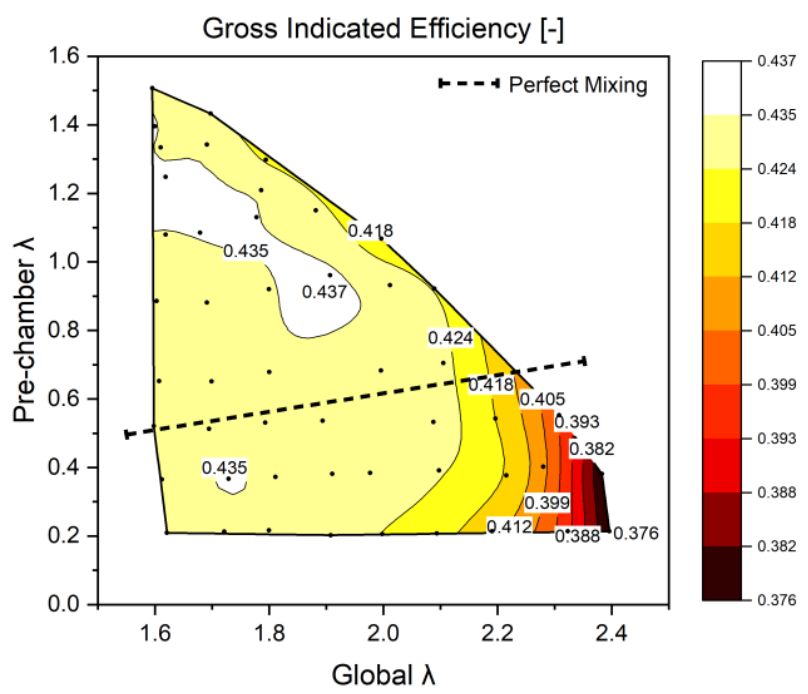

(c)

Figure 13 - Global $\lambda$ sweep with constant airflow - Efficiencies: (a) Combustion efficiency, (b) Thermodynamic efficiency, and (c) Gross indicated efficiency 
The trends between the two data-sets are in good agreement with each other, albeit the minor differences due to the effect of combustion efficiency. In the global $\lambda$ sweep with constant fuel flow, the in-cylinder pressure is increased as the global $\lambda$ becomes leaner due to higher intake pressures may lead to higher combustion efficiency of the main chamber charge since the reactivity of the airfuel mixture is improved at higher pressures. Apart from the minor differences, the trends are similar, and the operating in relatively rich global $\lambda$ between 1.3 and 1.5 is deemed unsatisfactory, owing to lower gross indicated efficiency and high NOx emissions. Note that the spark timing was fixed in this study, and therefore the efficiency values could be affected by the changes in combustion phasing.

\section{Heat Release Analysis}

For the heat release analysis, the pre-chamber and main chamber pressure traces are smoothened by spectral filtration using Fast Fourier Transform method. Only the high-frequency components are filtered out from the pressure traces, and the smoothen pressure traces are compared against the raw pressure trace to avoid over smoothening. The cut-off frequency of $3 \mathrm{kHz}$ is found to be optimal for both the pre-chamber and the main chamber pressure traces. The main chamber and pre-chamber heat release rates are calculated from the respective pressure traces for each cycle. The resulting heat release rates were ensemble-averaged for 200 cycles for both prechamber and main chamber. The pre-chamber $\lambda$ values, with the perfect displacement assumption, are rounded-off to one decimal point in presenting the data.

Plots are presented with pre-chamber and main chamber heat release along with the pressure difference between the two chambers. The convention for the pressure difference is taken to be positive when the pre-chamber pressure exceeds the main chamber pressure. In all the heat release plots, the solid lines represent the main chamber heat release rate, and the dotted lines are used for the pre-chamber heat release rate. The pre-chamber heat release rate is magnified five times for visibility. The dashed line displays the pressure difference between the two chambers.

An interesting observation is that the narrow throat pre-chamber typically features high pressure difference between the pre-chamber and the main chamber. Across all the operating conditions, the maximum pressure difference between the two chambers is around 40 bar, as shown in Figure 14, Figure 15, and Figure 17. For a similar pre-chamber volume and nozzle area, Shah et al. [15] reported a maximum pressure difference of around 23 bar in a similar size engine. The difference in maximum pressure difference could be attributed to narrow throat geometry, which is considered to increase the flow restriction, as reflected by the low value of the estimated discharge coefficient, which was found to be 0.34 from GT Power model calibration. The main chamber and pre-chamber pressure traces are presented in Appendix C.

The heat release analysis reveals a distinct two-step heat release profile for the main chamber heat release. The pre-chamber rate of heat release follows a Gaussian shape before the main chamber heat release rate starts to exceed the pre-chamber heat release. Beyond this point, the pre-chamber heat release rate becomes positive, indicating that there is an energy influx from the main chamber to the pre-chamber. After 5 CAD aTDC, the intensity of combustion in the main chamber declines. Although there is still a negative pressure difference suggesting backflow from the main chamber, the difference is reduced significantly. Referring to equation (2), the pre-chamber heat release rate becomes negative due to the negative pressure gradient of pre-chamber pressure. Although there is still energy input from the main chamber due to mass transfer, the contribution is small, and thus, the pre-chamber heat release rate becomes negative after $5 \mathrm{CAD}$ aTDC. The same behavior is observed for all the data points.

\section{Global $\lambda$ Sweep with Constant Fuel Flow}

Out of all the data-points, the three global $\lambda$ cases (global $\lambda$ of 1.3 , 1.6 , and 1.8) have been selected to explain the effect of pre-chamber enrichment on main chamber heat release characteristics. Only the stable operating points below the lean limit are presented here to avoid high cycle-to-cycle variations. Each of the global $\lambda$ cases is discussed in detail below.

\section{Case 1: Global $\lambda=1.3$, Intake Pressure $=1.3 \mathrm{bar}$}

The main chamber heat release rate can be segmented into three different stages - (a) initial heat release stage, (b) bulk heat release stage, and (c) post-burning stage. A representative heat release trace at global $\lambda=1.3$ and pre-chamber $\lambda=1.0$ is shown in Figure 14 . The initial heat release stage occurs when the pre-chamber jets are being issued into the main chamber, where the pre-chamber pressure starts to rise above the main chamber pressure. The heat release rate appears to slow down after a few crank angle degrees as a change of slope in the heat release rate is observed near the end of the initial heat release stage, denoted by (a) in Figure 14.

Around -7 CAD aTDC, there is a distinct change in the slope of the main chamber heat release rate. This stage is termed as the bulk heat release stage, where the majority of energy is released in the main chamber. This second stage is denoted by (b) in Figure 14. At this point, the pre-chamber heat release rate becomes positive again, indicating the energy input from the main chamber into the prechamber due to the backflow of combustion. The pressure difference between the two chambers also becomes negative at this point, further confirming the backflow. When operating at relatively rich conditions, around global $\lambda=1.3$, a small heat release event, which is termed a post-heat release stage, is observed in the main chamber heat release rate after the top-dead-center. For the case of global$\lambda=1.3$, the post-heat release stage is observable as a small bump in the heat release rate of the main chamber charge, around 7 CAD aTDC. The post-heat release stage is not observed when the overall $\lambda$ is lean.

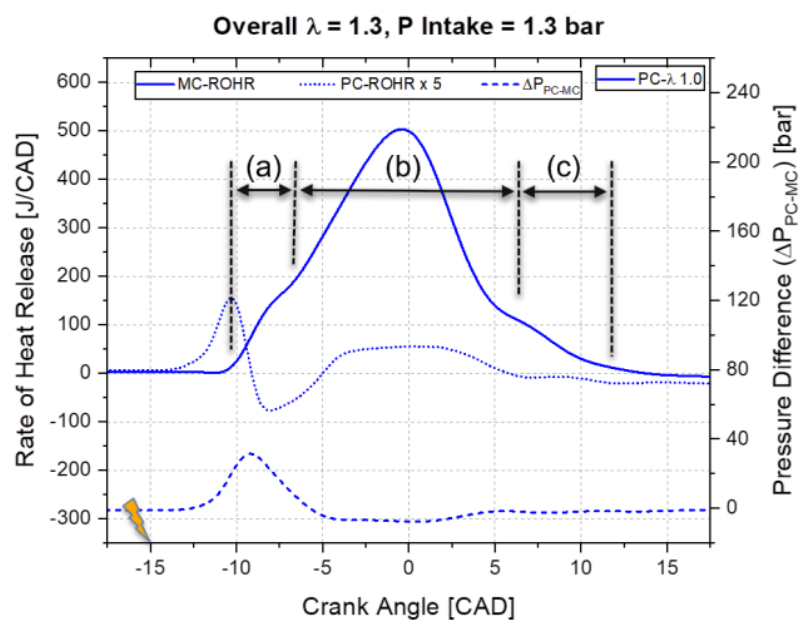

Figure 14 - Stages of main chamber heat release: (a) Initial heat release stage, (b) bulk heat release stage and (c) post-heat release stage

Page 11 of 19 
For the extremely-rich pre-chamber case, where pre-chamber $\lambda$ is around 0.3 , the pre-chamber heat release rate shows a delayed start compared to other pre-chamber enrichment levels, as shown in Figure 15 (a). The delay is very distinct compared to all the other cases and results in a delayed start of the main chamber's initial heat release stage. Thus, the flame development angle or the duration between the spark timing and $10 \%$ of total heat release (CA10) for the pre-chamber $\lambda=0.3$ case is significantly retarded, as shown in Figure 16 (a).

Subsequently, the $50 \%$ heat release angle or combustion phasing (CA50) is also retarded for this case, as observed in Figure 16 (b). From pre-chamber $\lambda=0.3$ to 1.0 cases, the combustion phasing is observed to be advancing as the pre-chamber $\lambda$ becomes less rich, with the pre-chamber $\lambda=1.0$ case showing the most advanced combustion phasing. Beyond pre-chamber $\lambda=1.0$, the combustion phasing becomes retarded again, perhaps due to lower fuel content in the pre-chamber. The combustion phasing (CA50) curve displays a minimum value centering on pre-chamber $\lambda=1.0$ and a concaving upward trend when moved away from pre-chamber $\lambda=1.0$. The curve is not symmetric and exhibits an increasing slope on the rich side of the pre-chamber $\lambda$.

The overall combustion durations (CA10-90) appear to be less sensitive to the pre-chamber $\lambda$, and the values are comparable for all pre-chamber $\lambda$ cases, as indicated in Figure 16 (c). From Figure 16 (a) and (b), it is evident that the pre-chamber enrichment affected the flame development angle and the combustion phasing (CA50). The lean limit of the pre-chamber is the passive case, and for the overall $\lambda$ of 1.3 , the pre-chamber $\lambda$ cannot be leaner than 1.3 .

\section{Case 2: Global $\lambda=1.6$, Intake Pressure $=1.5$ bar}

Similar to the global $\lambda=1.3$ cases, the extremely enriched prechamber shows a delayed start in pre-chamber ignition and thus retards the combustion phasing when global $\lambda=1.6$, as shown in Figure 15 (b). The combustion phasing appears to be advanced when approaching stoichiometry in pre-chamber $\lambda$. The pre-chamber $\lambda=$ 0.9 case shows the most advanced combustion phasing and shortest flame development angle. The combustion phasing is retarded when the pre-chamber $\lambda$ is leaner than stoichiometry since the start of the pre-chamber heat release is retarded at these conditions. The peak heat release rate of the pre-chamber also decreases as the prechamber $\lambda$ increases.

As indicated in Figure 15 (b), the heat release rates of enriched prechamber cases are observed to be significantly lower than the prechamber $\lambda$ close to stoichiometry or relatively lean pre-chambers. For the extremely rich pre-chamber case of $\lambda=0.4$, the two-stage heat release profile is very distinct, and as the pre-chamber $\lambda$ becomes lean, the slopes of heat release rate are less pronounced. As in the previous case, the effect of pre-chamber $\lambda$ on flame development angle and the combustion phasing can be observed in Figure 16 (a) and (b). The overall combustion duration (CA10-90) is also comparable between the different pre-chamber $\lambda$, although the main chamber ignition is late in some cases, as indicated in Figure 16 (c). Compared to the global $\lambda=1.3$ case, the post burning stage is found to be absent, which can be attributed to the lean air-fuel mixture in the main chamber.

\section{Case 3: Global $\lambda=1.8$, Intake Pressure $=1.7$ bar}

As observed in Figure 15 (c), the extremely enriched pre-chamber case (pre-chamber $\lambda=0.4$ ) also displays a delayed start, similar to the previous cases. Compared to case 1 and case 2, as the intake pressure increases, the flame development angle reduces, probably due to the higher reactivity of the air-fuel mixtures at elevated pressures. The distinct two-stage heat release profile is observed for all the cases. However, for the leanest pre-chamber case (prechamber $\lambda=1.3$ ), the slope changes are less pronounced.

The richest pre-chamber $\lambda$ case still shows the delayed start of the pre-chamber heat release. However, the start of pre-chamber heat release in the richest and the leanest pre-chamber $\lambda$ cases are almost the same, albeit the heat release rate being lower for the leaner prechamber $\lambda$. Since the global $\lambda$ is fixed, enriching the pre-chamber resulted in lower fuel energy in the main chamber charge. Hence, the leaner pre-chamber $\lambda$ case has a higher mixture strength in the main chamber, which manifests to comparatively higher main chamber heat release rate than the richest pre-chamber $\lambda$ case.

The maximum value of the main chamber heat release rate appears to be dependent on the phasing of heat release and the pre-chamber $\lambda$. For this global $\lambda$, the peak main chamber heat release rate is observed when the pre-chamber $\lambda$ is 1.1 . The post-burning stage is also absent in this case. The flame development angle and the combustion phasing are also affected by the pre-chamber enrichment level, as shown in Figure 16 (a) and (b). As in the previous cases, the combustion duration is largely insensitive to the variation in pre-chamber $\lambda$, which can be observed in Figure 16 (c).

\section{Global $\lambda$ Sweep with Constant Air Flow}

Among the data collected, the three cases with global $\lambda=1.6,1.8$, and 2.0 are presented to explain the behavior of pre-chamber enrichment. As in the previous section, only stable operating points below the combustion stability limit are shown in this section. Each of the global $\lambda$ is discussed as follows.

\section{Case 1: Global $\lambda=1.6$, Intake Pressure $=1.5$ bar}

Similar to the first methodology, the extremely enriched prechamber cases (pre-chamber $\lambda=0.2$ and 0.4 ) display a distinct delay of the start of the pre-chamber heat release, as observed in Figure 17 (a). The most advanced combustion phasing is achieved at prechamber $\lambda=0.7$, and this case also exhibits the highest rate of main chamber heat release. The pre-chamber $\lambda=1.1$ case also indicates a similar start of the pre-chamber heat release compared to the prechamber $\lambda=0.7$. In contrast, the pre-chamber heat release rate diminishes at a faster rate, and therefore, a slightly delayed and reduced main chamber heat release rate is observed.

In the two lean pre-chamber (pre-chamber $\lambda=1.1$ and 1.4) cases, the gradients of the initial and bulk heat release rate are much smaller, resulting in the main chamber heat release rate resembling a Gaussian curve. The main chamber heat release is also retarded, resulting in prolonged flame development angle and late combustion phasing, as shown in Figure 18 (a) and (b). Apart from these two cases, a distinct two-stage heat release phenomenon is observed. The characteristic $\mathrm{u}$-shaped curves for the flame development angle and the combustion phasing (CA50) are also observed for this global $\lambda$ case, as indicated in Figure 18 (a) and (b). The combustion duration is also largely insensitive to pre-chamber $\lambda$, as shown in Figure 18 (c). No post-burning stage is observed.

\section{Case 2: Global $\lambda=1.8$, Intake Pressure $=1.5 \mathrm{bar}$}

Distinct delayed start of pre-chamber heat release for the extremely rich pre-chamber (pre-chamber $\lambda=0.2$ ) is detected, as shown in Figure 17 (b). As in the previous cases, two-stage heat release rate profile for the main chamber is observed for enriched pre-chamber 


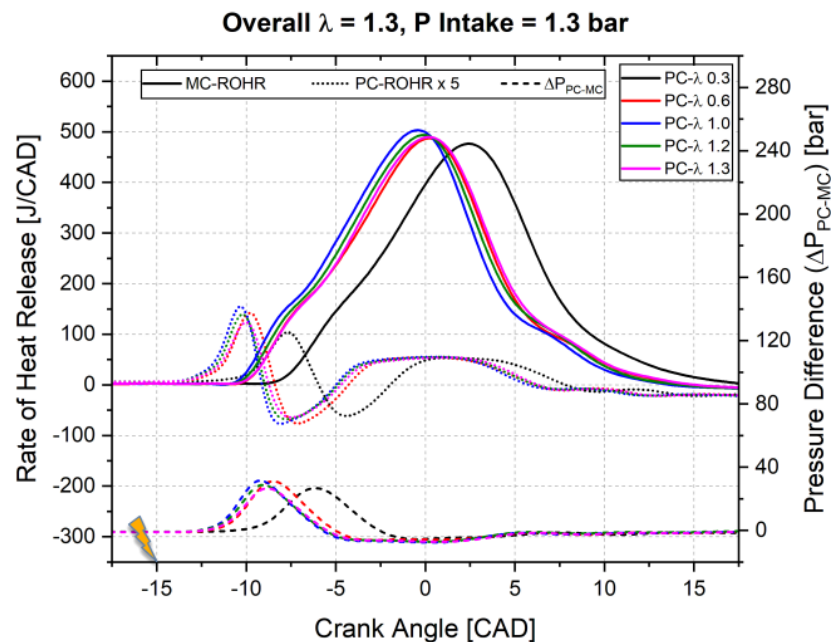

(a)

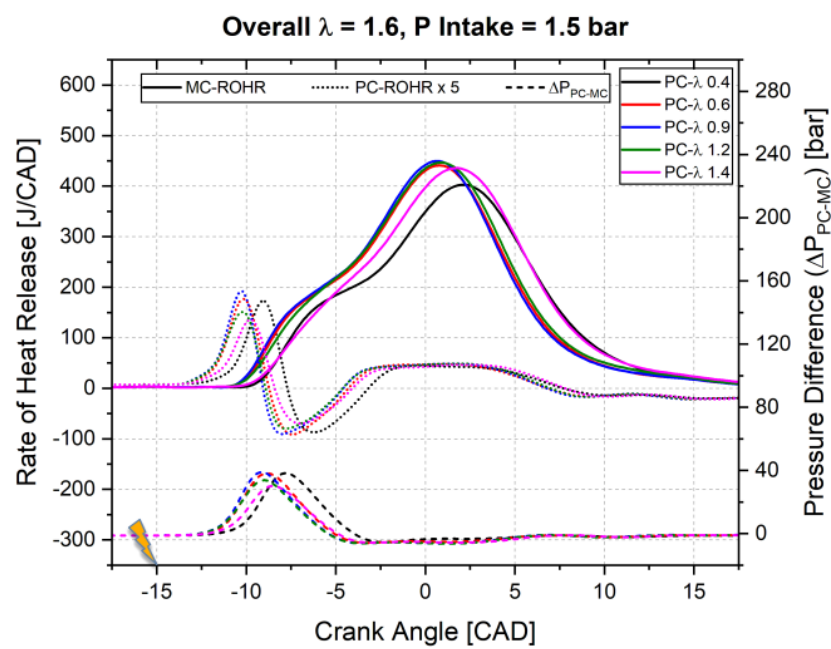

(b)

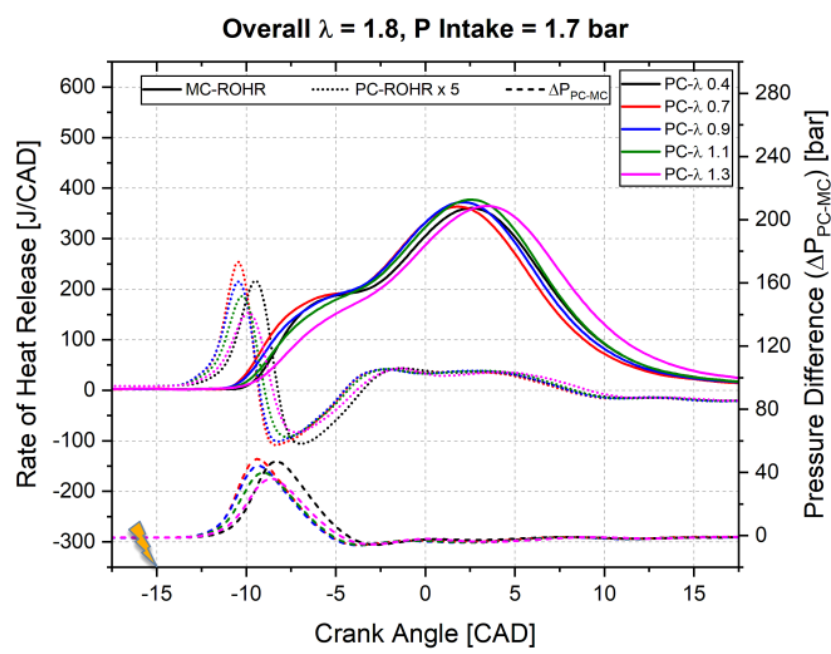

(c)

Figure 15 - Global $\lambda$ sweep with constant fuel flow - Rate of heat release and pressure difference between the pre-chamber and the main chamber for different pre-chamber $-\lambda$ : (a) Overall $\lambda=1.3$, (b) Overall $\lambda=1.6$, and (c) Overall $\lambda=1.8$

Page 13 of 19

$01 / 28 / 2020$

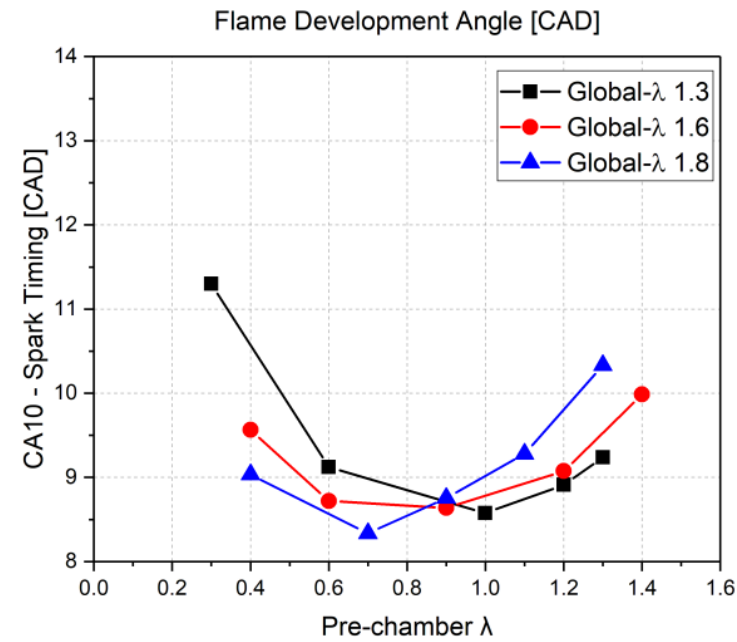

(a)

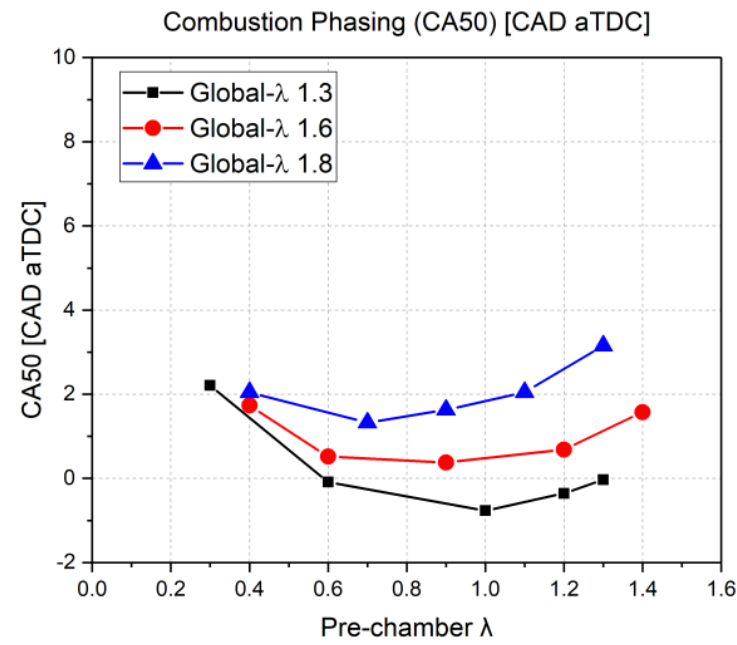

(b)

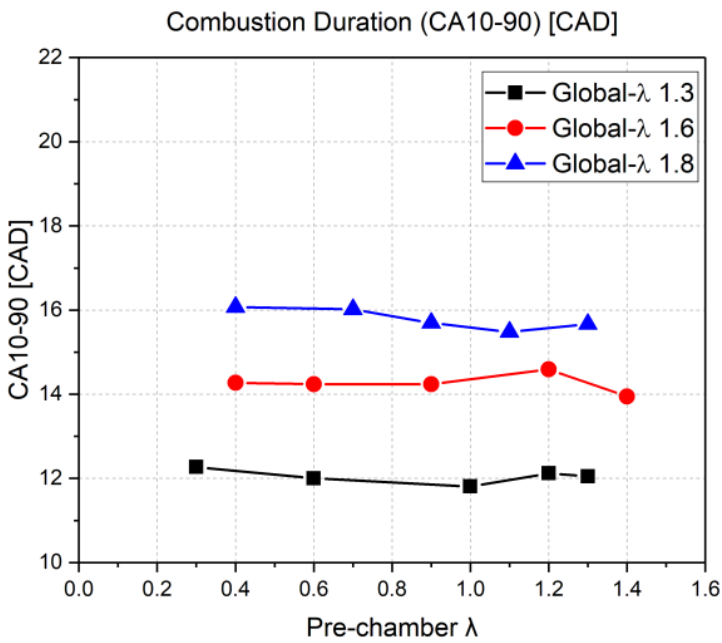

(c)

Figure 16 - Global $\lambda$ sweep with constant fuel flow - Heat release analysis for different pre-chamber $\lambda$ at Overall $\lambda=1.3,1.6$ and 1.8: (a) Flame development Angle, (b) combustion phasing and (c) combustion duration 


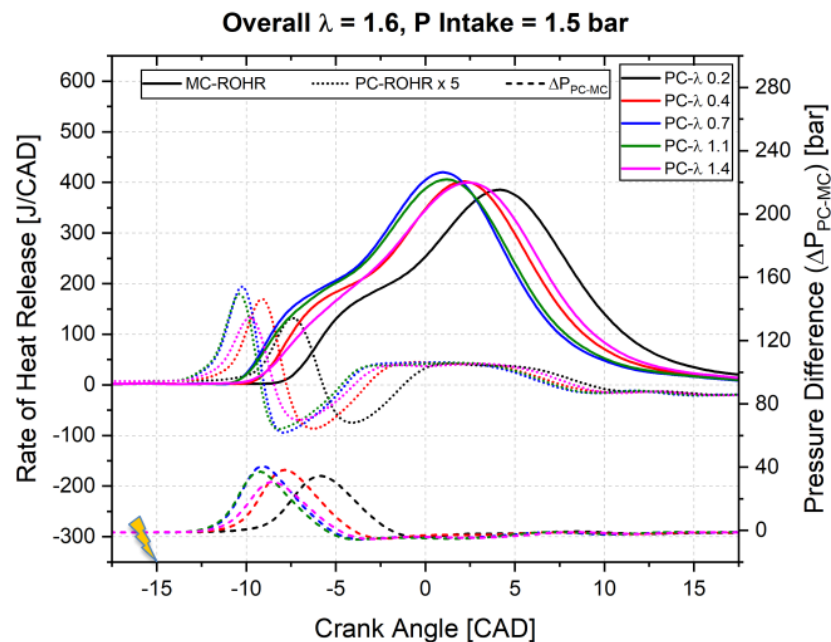

(a)

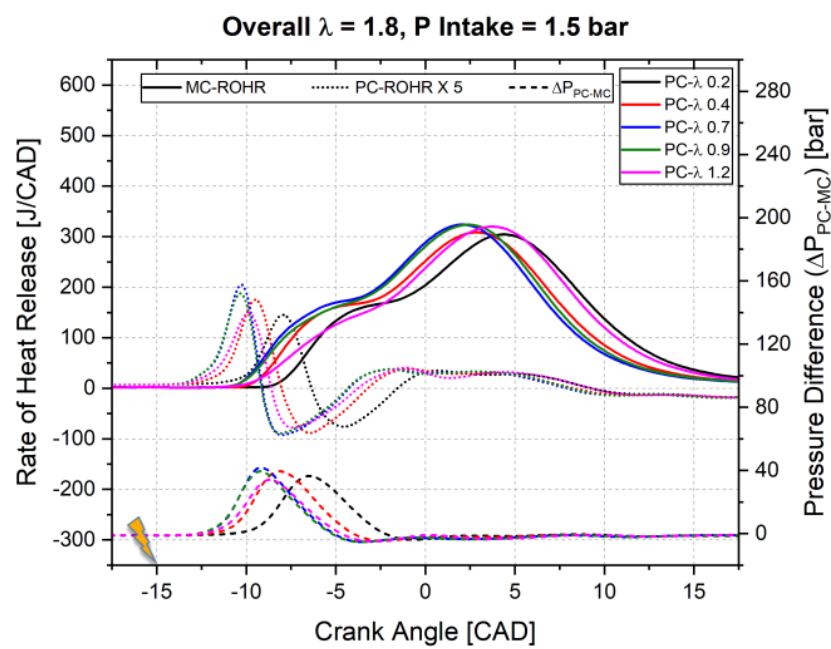

(b)

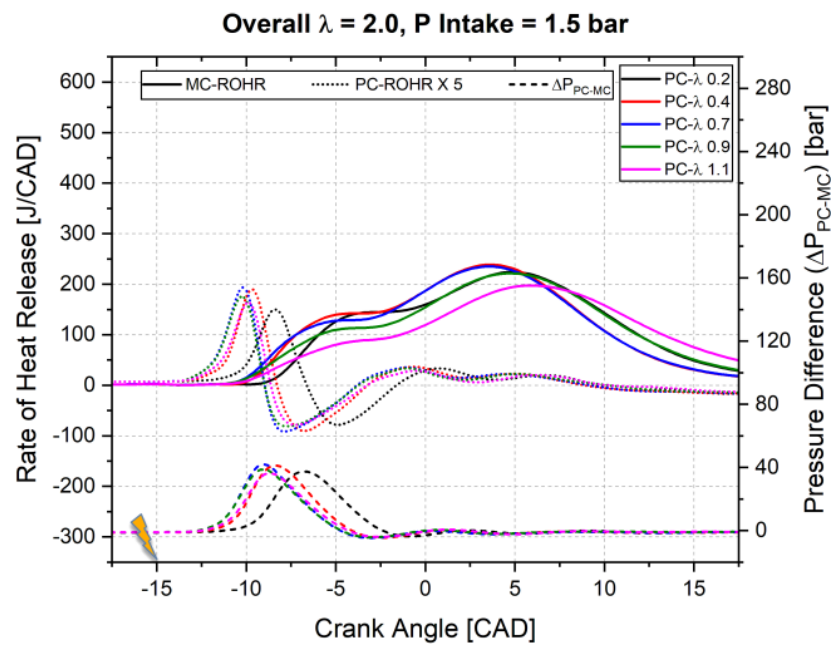

(c)

Figure 17 - Global $\lambda$ sweep with constant airflow - Rate of heat release and pressure difference between the pre-chamber and the main chamber for different pre-chamber $\lambda$ : (a) Overall $\lambda=1.6$, (b) Overall $\lambda=1.8$, and (c) Overall $\lambda=2.0$

Page 14 of 19

$01 / 28 / 2020$

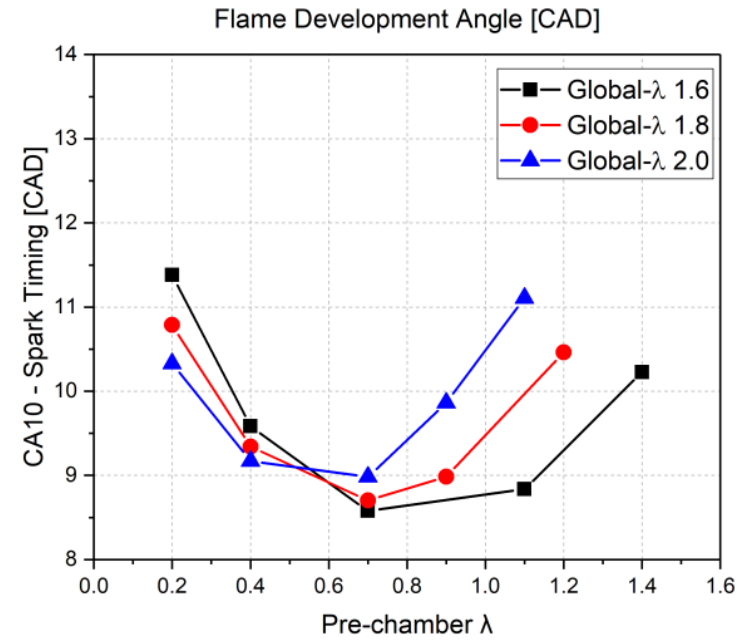

(a)

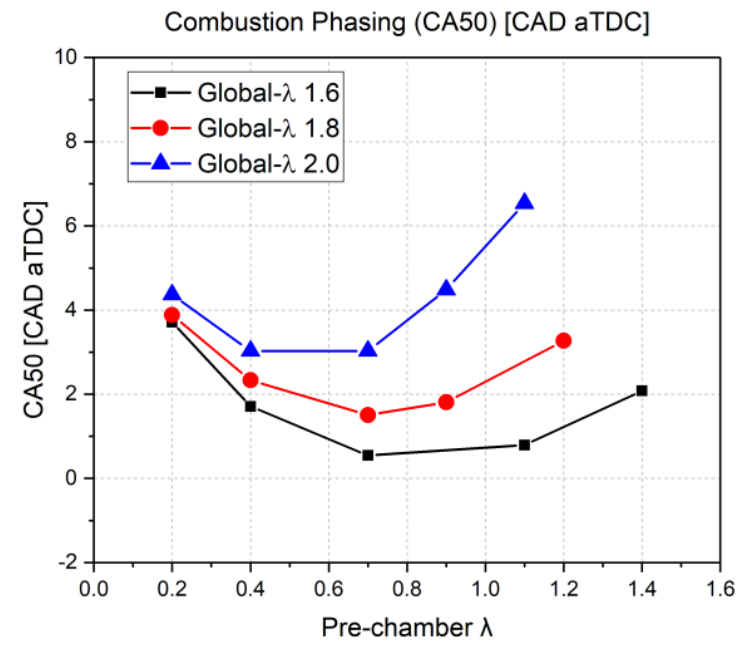

(b)

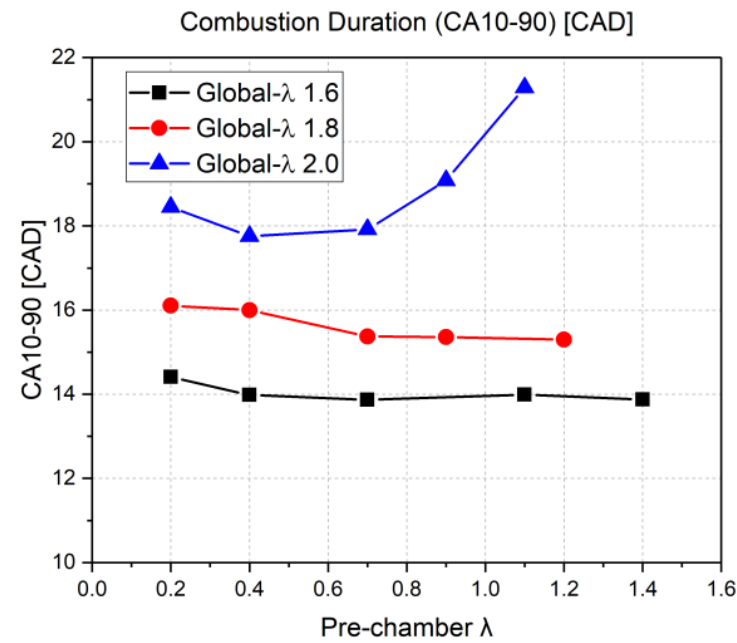

(c)

Figure 18 - Global $\lambda$ sweep with constant airflow - Heat release analysis for different pre-chamber $\lambda$ at Overall $\lambda=1.6,1.8$ and 2.0: (a) Flame

Development Angle, (b) Combustion Phasing and (c) Combustion Duration 
cases (pre-chamber $\lambda<1$ ). The profile of the main chamber heat release rate is closer to a Gaussian shape for the pre-chamber $\lambda=$ 1.2 , indicating a slower burn rate. Since the global $\lambda$ is lean, there is no observable post-burning stage in the heat release trace.

Similar to previous cases, the shortest flame development angle and most advanced combustion phasing are achieved at the pre-chamber $\lambda=0.7$, as shown in Figure 18 (a) and (b). Since the global $\lambda$ is leaner than in previous cases, longer combustion durations are observed, as indicated in Figure 18 (c). The overall combustion durations are not significantly affected by pre-chamber enrichment, although slightly slower combustion rates are observed for the two extremely rich prechamber cases (pre-chamber $\lambda=0.2$ and 0.4 ).

\section{Case 3: Global $\lambda=2.0$, Intake Pressure $=1.5$ bar}

Identical to the previous two cases, the pre-chamber heat release starts with a delay for the extremely enriched pre-chamber (prechamber $\lambda=0.2$ ) case, as shown in Figure 17 (c). In addition, the shortest flame development angle and the most advanced combustion phasing is observed at the pre-chamber $\lambda=0.7$, as observed in Figure 18 (a) and (b). On the other hand, the leanest prechamber case (pre-chamber $\lambda=1.1$ ) exhibits a longer flame development angle compared to all the cases.

In contrast to the global $\lambda$ of 1.6 and 1.8 cases, the total combustion durations (CA10-90) of the two leanest pre-chamber $\lambda$ cases are significantly longer than the rich pre-chamber cases, as observed in Figure 18 (c). Inspecting the heat release traces reveals slower and prolonged heat release rates for these two cases, as indicated in Figure 17 (c). A drop in the intensity of pre-chamber heat release is observed for pre-chamber $\lambda$ leaner than 0.7 , with a corresponding decline in the pressure difference between the two chambers. The post-burning stage is not detected in this global $\lambda$, as well.

\section{Conclusion}

1. The indicated efficiency and emission characteristics are largely dependent on the global $\lambda$ and are insensitive to the prechamber $\lambda$. The specific NOx emissions values are excessive at relatively rich global $\lambda$ conditions and decline as the global $\lambda$ increased. Inversely, the specific carbon monoxide and the hydrocarbon emissions increase as the global $\lambda$ increases.

2. The poor combustion efficiency, especially at the lean conditions, would incur a penalty on greenhouse gas (GHG) emissions since methane is considered to be more potent than $\mathrm{CO}_{2}$. From both efficiency and emission standpoint, the combustion efficiency needs to be further improved to realize a significant reduction in $\mathrm{GHG}$ emissions.

3. With the narrow throat geometry, the indicated efficiency is found to be lower than conventional diesel efficiencies. The fact that the thermodynamic efficiency being lower at air-fuel ratios close stoichiometry takes a toll on gross indicated efficiency. The thermodynamic efficiency is improved at lean conditions. However, the combustion efficiency declines rapidly as the air-fuel ratios become leaner, which prevents the concept from achieving higher gross indicated efficiencies relevant to diesel engines.

4. Three stages of heat release are observed in the main chamber heat release rate, which is termed as (a) the initial heat release stage, (b) the bulk heat release stage, and (c) the post-heat release stage. The first stage of the main chamber heat release can be contributed to the pre-chamber jets being issued into the main chamber. The second stage indicates the bulk ignition of the main chamber charge. The post-heat release stage is only observed in global $\lambda=1.3$ cases and was not observed at leaner conditions.

5. For the two different assumptions for the pre-chamber trapped fuel, if the perfect mixing scenario has been close to reality, the pre-chamber enrichment levels below the perfect mixing limit should exhibit similar characteristics for the main chamber heat release. However, this has not been the case, and the prechamber appears to be richer with the increasing amount of fuel injection.

6. The extremely rich pre-chamber cases (pre-chamber $\lambda \leq 0.4$ ) typically show a longer ignition delay and relatively slower pressure rise rates in pre-chamber pressure. However, the peak pressure values are comparable to other pre-chamber $\lambda$ conditions, and the main chamber heat release does not appear to be affected significantly apart from the shifting of combustion phasing.

7. The total combustion duration (CA10-90) is observed to increase with increasing global $\lambda$. For most global $\lambda$ conditions, although the flame development angle and combustion phasing (CA50) are different for different pre-chamber $\lambda$, the total combustion duration is relatively flat, which suggests that the total combustion duration is not affected by pre-chamber $\lambda$.

\section{References}

[1] European Climate Foundation (ECF), "Roadmap 2050: A practical guide to a prosperous, low-carbon europe," In: Energy Accounts Architectural Representation of Energy, Climate, and the Future. (2016), 69.doi:10.4324/9781315690995.

[2] Joint Research Center - European Commission, "EU renewable energy targets in 2020: Revised analysis of scenarios for transport fuels.", (2014).

[3] British Petroleum, "BP Energy Outlook 2019 edition The Energy Outlook explores the forces shaping the global energy transition out to 2040 and the key uncertainties surrounding that," In: BP Energy Outlook 2019 (2019).

[4] Date, T., Yagi, S., Ishizuya, A., and Fujii, I., "Research and Development of the Honda Cvec Engine.," SAE Technical Paper 740605, 1974, doi:10.4271/740605.

[5] Brandstetter, W. " "The Volkswagen Lean Burn PC-Engine Concept," SAE Technical Paper 800456, 1980, doi: $10.4271 / 800456$.

[6] Noguchi, M., Sanda, S., and Nakamura, N., "Development of toyota lean burn engine", SAE Technical Paper 760757, 1976, doi:10.4271/760757.

[7] Alvarez, C.E.C., Couto, G.E., Roso, V.R., Thiriet, A.B., and Valle, R.M., "A review of prechamber ignition systems as lean combustion technology for SI engines," Applied Thermal Engineering 128:107-20, 2018.

[8] Toulson, E., Schock, H.J., and Attard, W.P., "A Review of Pre-Chamber Initiated Jet Ignition Combustion Systems", SAE Technical Paper 2010-01-2263, 2010, doi:10.4271/2010-01-2263.

[9] Gussak, L.A., Karpov, V.P., and Tikhonov, Y.V., "The Application of Lag-Process in Prechamber Engines," SAE Technical Paper 790692, 1979, doi:10.4271/790692.

[10] Gholamisheeri, M., Wichman, I.S., and Toulson, E., “A study of the turbulent jet flow field in a methane fueled turbulent jet ignition (TJI) system," Combustion and Flame 183:194-206, 2017.

[11] Oppenheim, A.K., "Prospects for Combustion in Piston Engines," SAE Technical Paper 2002-01-0999, 2002, doi:10.427/2002-01-0999.

[12] Yamaguchi, S., Ohiwa, N., and Hasegawa, T., "Ignition and burning process in a divided chamber bomb,"

Page 15 of 19 
Combustion and Flame 59 (2):177-87, 1985.

[13] Biswas, S., \& Qiao, L., "Ignition of ultra-lean premixed H2/air using multiple hot turbulent jets generated by prechamber combustion," Applied Thermal Engineering 132:102-14, 2018.

[14] Gentz, G., Thelen, B., Gholamisheeri, M., Litke, P., Brown, A., Hoke, J., and Toulson, E. "A study of the influence of orifice diameter on a turbulent jet ignition system through combustion visualization and performance characterization in a rapid compression machine," Applied Thermal Engineering 81:399-411, 2015.

[15] Shah, A., Tunestal, P., and Johansson, B., "Effect of PreChamber Volume and Nozzle Diameter on Pre-Chamber Ignition in Heavy Duty Natural Gas Engines," SAE Technical Paper 2015-01-0867, 2015, doi:10.4271/201501-0867.

[16] Bardis, K., Xu, G., Kyrtatos, P., Wright, Y.M., and Boulouchos, K., "A Zero Dimensional Turbulence and Heat Transfer Phenomenological Model for Pre-Chamber Gas Engines," SAE Technical Paper 2018-01-1453, 2018, doi:10.4271/2018-01-1453.

[17] Shapiro, E., Tiney, N., Kyrtatos, P., Kotzagianni, M., Bolla, M., Boulouchos, K., Tallu, G., Lucas, G., and Weissner, M., "Experimental and Numerical Analysis of Pre-Chamber Combustion Systems for Lean Burn Gas Engines," SAE Technical Paper 2019-01-0260, 2019, doi:10.4271/2019-01-0260.

[18] Attard, W., Fraser, N, Parsons, P., and Toulson, E., "A Turbulent Jet Ignition Pre-Chamber Combustion System for Large Fuel Economy Improvements in a Modern Vehicle Powertrain," SAE Int. J. Engines 3(2):20-37, 2010, doi:10.4271/2010-01-1457.

[19] Shah, A., Tunestal, P., and Johansson, B., "Effect of relative mixture strength on performance of divided chamber 'Avalanche activated combustion' Ignition technique in a heavy duty natural gas engine," SAE Technical Paper 2014-01-1327, 2014, doi:10.4271/201401-1327.

[20] Duong, J., Andersson, Ö., Hyvönen, J., Álden, M., Wellander, R., Johansson, B., and Richter, M., "HighSpeed Combustion Imaging in a Large Bore Gas Engine: The Relationship Between Pre- and Main Chamber Heat Release," In Volume 8A: Heat Transfer and Thermal Engineering, V08AT09A022, ASME 2014.

[21] Hlaing, P., Echeverri Marquez, M., Bhavani Shankar, V.S., Cenker, E., Ben Houidi, M., and Johansson, B., “A Study of Lean Burn Pre-Chamber Concept in a Heavy Duty Engine,” SAE Technical Paper 2019-01-0107, 2019, doi:10.4271/2019-01-0107.

[22] Heywood, J.B., "Internal Combustion Engine Fundamentals", McGraw-Hill, 1998.

[23] Gussak, L.A., Turkish, M.C., Siegla, D.C., "High Chemical Activity of Incomplete Combustion Products and a Method of Prechamber Torch Ignition for Avalanche Activation of Combustion in Internal Combustion Engines," SAE Technical Paper 750890, 1975, doi: $10.4271 / 750890$.

[24] Moffat, R.J., "Describing the uncertainties in experimental results", Experimental Thermal and Fluid Science. 1, 1988, doi:10.1016/0894-1777(88)90043-X.

[25] Sharma, P., \& Dhar, A., "Effect of hydrogen supplementation on engine performance and emissions," International Journal of Hydrogen Energy. 43 , 2018, doi:10.1016/j.ijhydene.2018.02.181.

[26] Olsen, D.B., \& Lisowski, J.M., "Prechamber NOx formation in low BMEP 2-stroke cycle natural gas

engines", Applied Thermal Engineering. 29 , 2009, doi:10.1016/j.applthermaleng.2008.03.049.

\section{Contact Information}

\section{Ponnya Hlaing \\ Ph.D. Student}

Clean Combustion Research Center (CCRC)

Internal Combustion Engine Lab

King Abdullah University of Science and Technology (KAUST)

Thuwal, Saudi Arabia

ponnya.hlaing@kaust.edu.sa

Phone no: +966 565485657

\section{Acknowledgments}

The paper is based upon work supported by Saudi Aramco Research and Development Center FUELCOM3 program under Master Research Agreement Number 6600024505/01. FUELCOM (Fuel Combustion for Advanced Engines) is a collaborative research undertaking between Saudi Aramco and KAUST intended to address the fundamental aspects of hydrocarbon fuel combustion in engines, and develop fuel/engine design tools suitable for advanced combustion modes.

The author would like to thank King Abdullah University of Science and Technology (KAUST) and the Clean Combustion Research Center (CCRC) for lab facilities and research support. Last but not least, the authors would like to convey gratitude towards the IC Engine Lab Safety Supervisor Adrian I. Ichim and the lab technician Riyad H. Jambi for their kind input and assistance in performing the experiments.

\section{Abbreviations}

$A_{T}$

CA10

CA50

CA90

CAD aTDC

$\boldsymbol{C}_{\boldsymbol{d}}$

CI

$C_{P}$

CVCC

DOI
Total area of nozzle holes

Crank angle at $10 \%$ of cumulative heat release

Crank angle at $50 \%$ of cumulative heat release

Crank angle at $90 \%$ of cumulative heat release

Crank angle degree after top-deadcenter

Discharge coefficient through the pre-chamber

Compression ignition

Mixture-averaged specific heat at constant pressure

Compound vortex controlled combustion

Duration of injector opening

Page 16 of 19 
Homogeneous charge compression ignition

Excess air ratio

Lub. Oil

Lubricating oil

m

Mass transferred between the prechamber and the main chamber

MC

Main chamber

$P_{M C}$

$P_{P C}$

PC

PPC

ppm

$Q_{M C}$

$Q_{M C}$

$\boldsymbol{R}$

SACI

SI

$T_{M C}$

$\boldsymbol{T}_{P C}$

$V_{M C}$

$V_{P C}$

$\gamma$

$\boldsymbol{\theta}$
Main chamber pressure

Pre-chamber pressure

Pre-chamber

Partially premixed combustion

Parts per million

Main chamber cumulative heat release

Pre-chamber cumulative heat release

Mixture-averaged gas constant

Spark-assisted compression ignition

Spark ignition

Temperature of main chamber air-fuel mixture

Temperature of prechamber air-fuel mixture

Main chamber volume

Specific heat ratio

Crank angle degree
Pre-chamber volume

\section{Appendix A - Uncertainty Analysis of Pre- chamber Excess Air Ratio}

The estimation of pre-chamber $\lambda$ relies on the six parameters mentioned in Table A1. The overall uncertainty due to instrument accuracies is calculated using equation (8) [24].

$$
\frac{\Delta S}{S}=\sqrt{\left(\frac{\Delta x_{1}}{x_{1}}\right)^{2}+\left(\frac{\Delta x_{2}}{x_{2}}\right)^{2}+\left(\frac{\Delta x_{3}}{x_{3}}\right)^{2}+\cdots+\left(\frac{\Delta x_{n}}{x_{n}}\right)^{2}}
$$

$\mathrm{S}$ is the value of the estimated quantity, which in this case is the prechamber $\lambda$, and $x_{1}, x_{2}, x_{3}, \ldots, x_{n}$ are the mean values of the independent variables. In the case of the main chamber pressure, the average value of the peak in-cylinder pressure value is used. The individual instrument error of each independent variable is given by $\left(\frac{\Delta x_{n}}{x_{n}}\right)$, where $\Delta x_{n}$ is the accuracy of the particular independent variable [25]. The relative errors of the individual instruments for all the data-points are calculated, and the maximum relative error of each instrument is presented in Table A1.

Table A.1 - Relative error of instruments contribution to uncertainty of prechamber $\lambda$

\begin{tabular}{|l|l|l|}
\hline & Independent variable & Relative error \\
\hline 1. & Main chamber pressure & $1.7 \%$ \\
\hline 2. & Pre-chamber fuel flow & $15.2 \%$ \\
\hline 3. & Main chamber fuel flow & $3.0 \%$ \\
\hline 4. & Intake air temperature & $7.3 \%$ \\
\hline 5. & Exhaust gas temperature & $0.5 \%$ \\
\hline 6. & Airflow rate & $4.5 \%$ \\
\hline
\end{tabular}

From equation (8), the total uncertainty associated with the determination of pre-chamber $\lambda$ is $20.8 \%$. Note that the relative error of the pre-chamber fuel flow measurement is high because, in some operating points, the pre-chamber fuel flow is at the lower end of the calibrated operating range and thus resulted in high uncertainty. 


\section{Appendix B - Flame Development Angle, Combustion Phasing and Combustion Duration}

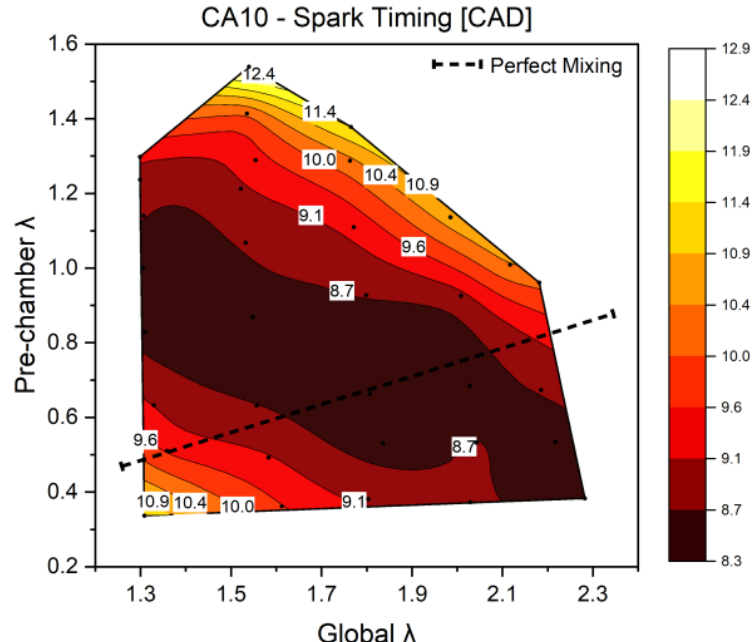

(a)

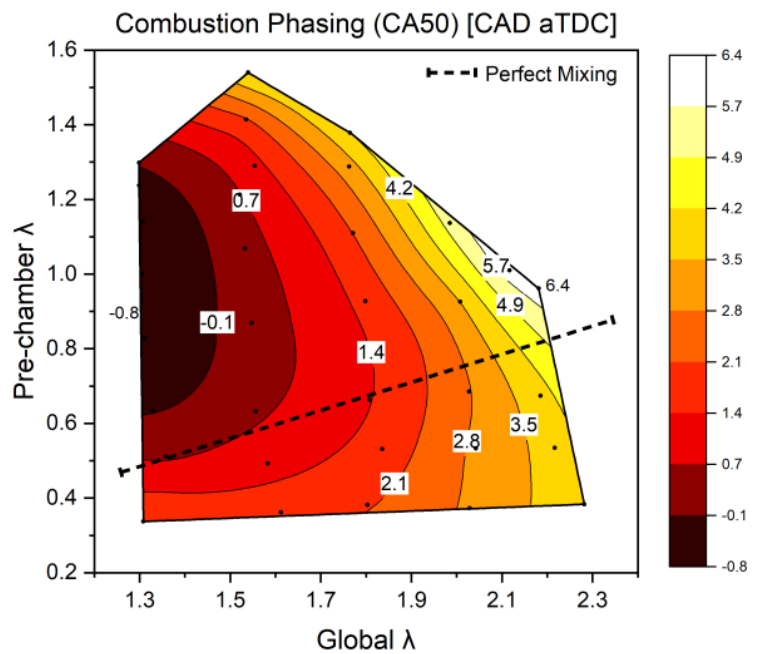

(b)

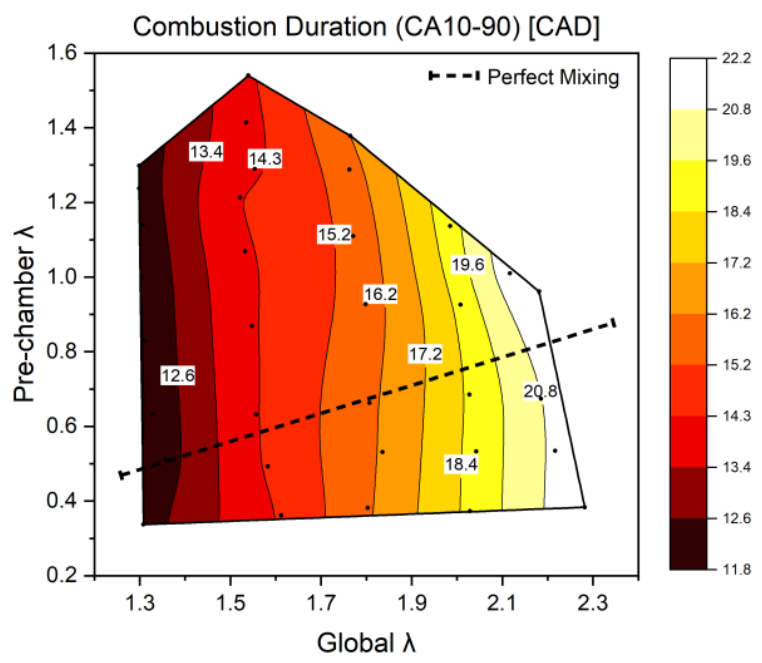

(c)

Figure B.1 1 - Global $\lambda$ sweep with constant fuel flow - Heat release data: (a) Flame development angle, (b) Combustion phasing (CA50) and (c) Combustion duration (CA10-90)

Page 18 of 19

$01 / 28 / 2020$

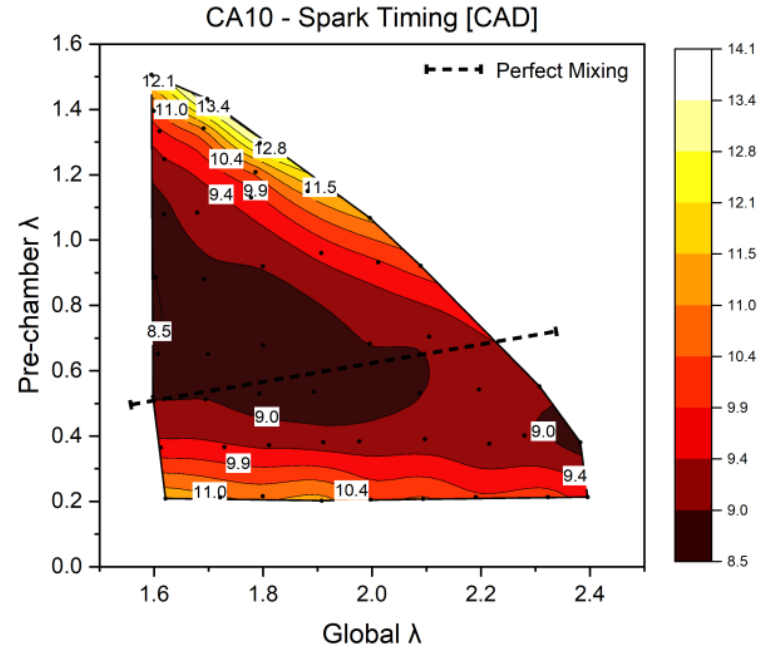

(a)

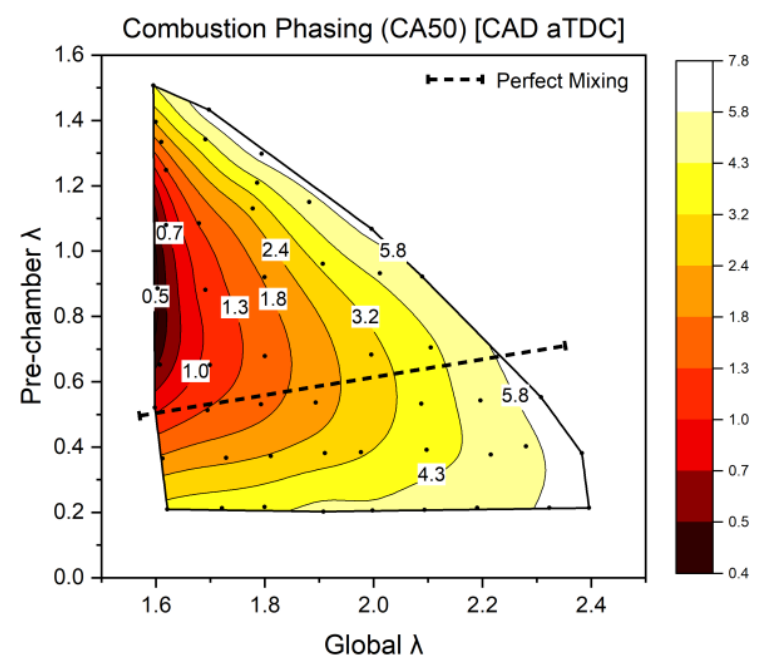

(b)

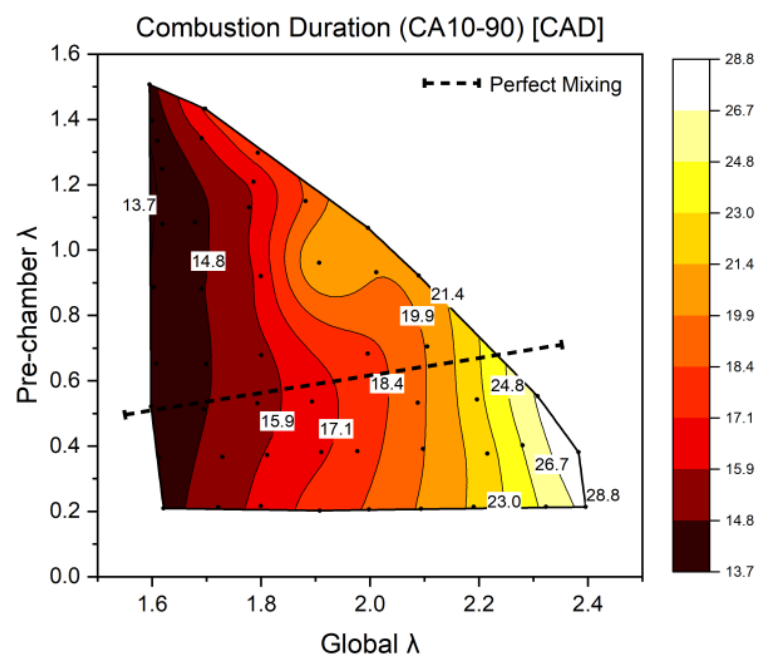

(c)

FigureB. 22 - Global $\lambda$ sweep with constant airflow - Heat release data: (a) Flame development angle, (b) Combustion phasing (CA50) and (c) Combustion duration (CA10-90) 
Appendix C - Pre-chamber and Main Chamber Pressure Traces

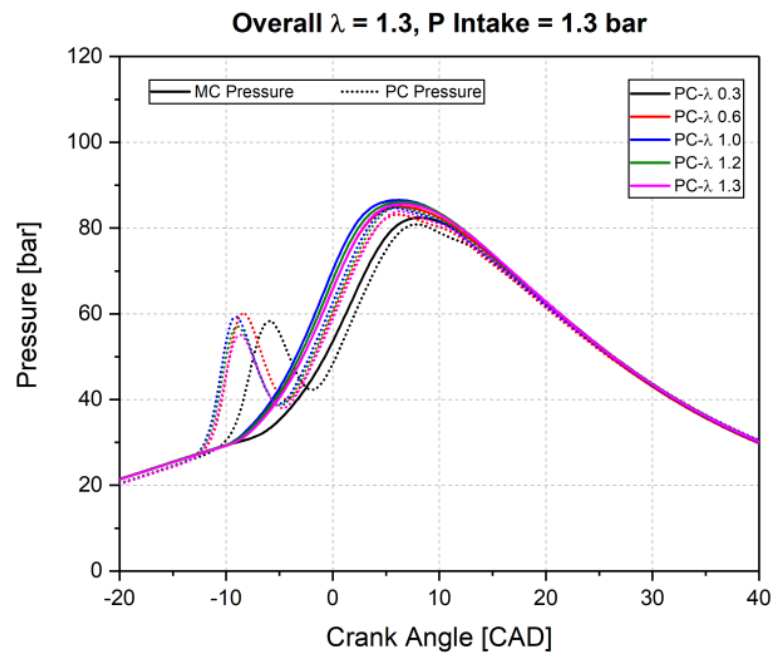

(a)

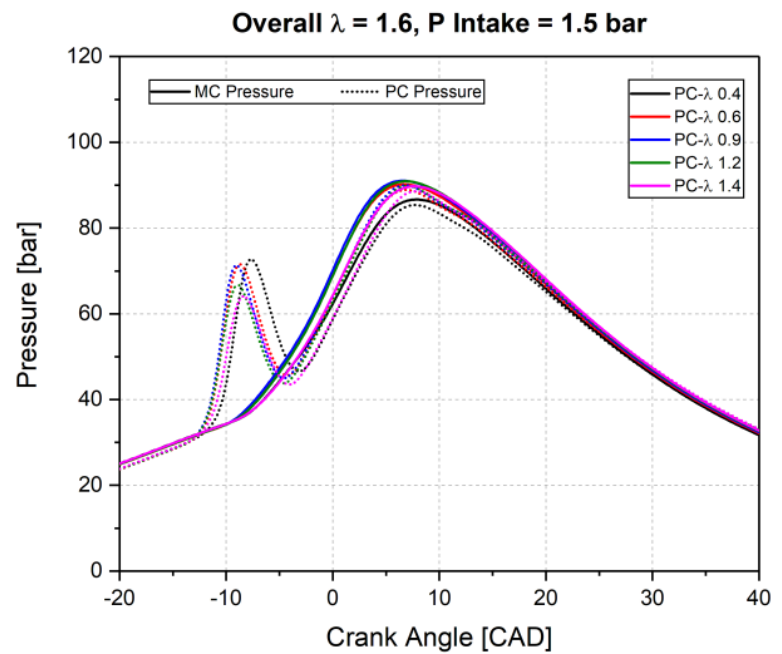

(b)

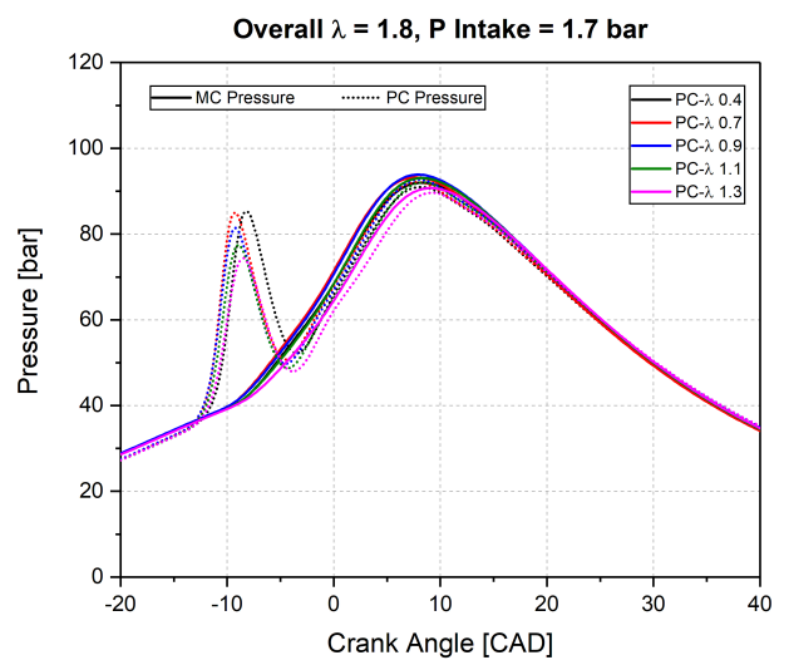

(c)

FigureC.1 1 - Global $\lambda$ sweep with constant fuel flow - main chamber and pre-chamber pressure traces: (a) Overall $\lambda=1.3$, (b) Overall $\lambda=1.6$, and (c) Overall $\lambda=1.8$

Page 19 of 19

$01 / 28 / 2020$

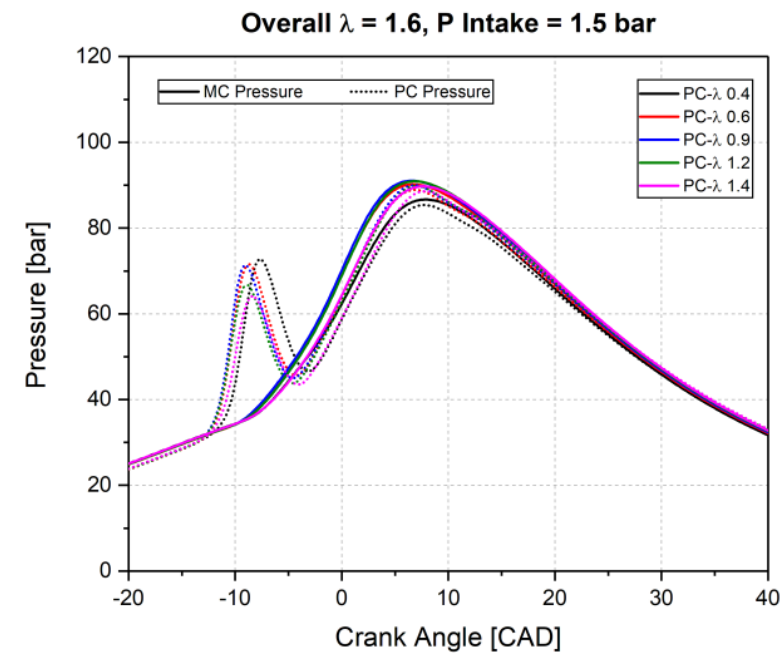

(a)

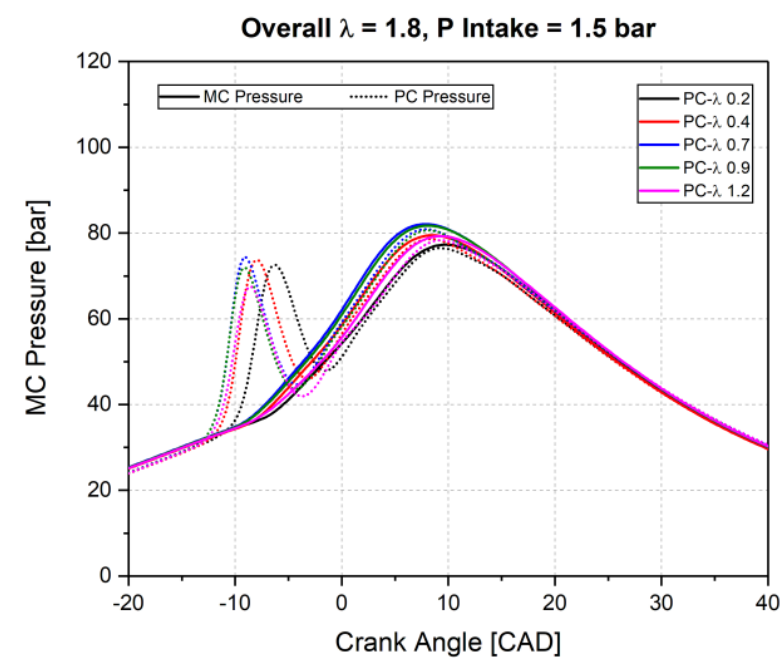

(b)

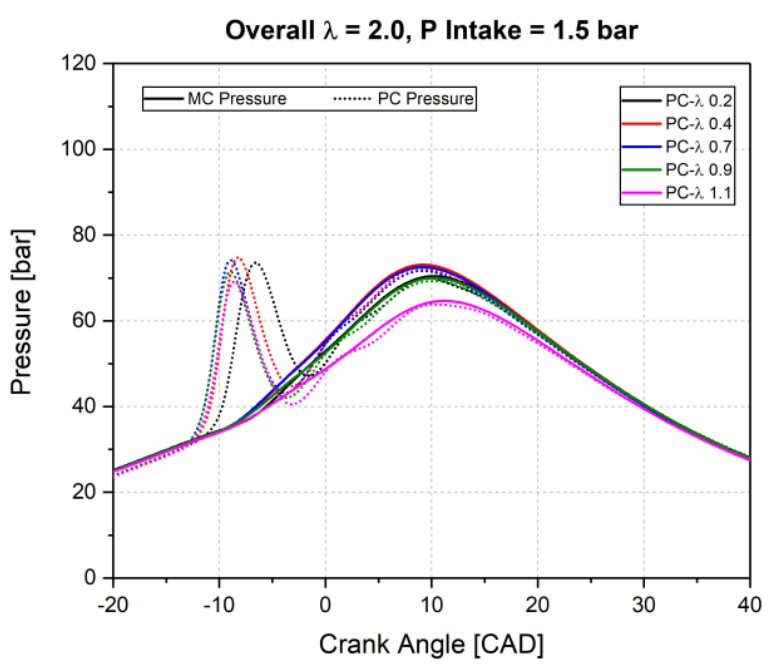

(c)

FigureC.2 1 - Global $\lambda$ sweep with constant airflow - main chamber and pre-chamber pressure traces: (a) Overall $\lambda=1.6$, (b) Overall $\lambda=1.8$, and (c) Overall $\lambda=2$ 